MELISSA MORAIS DE CASTRO GONÇALVES

INFLUÊNCIA DOS AGENTES IRRIGANTES, TEMPO PÓSTRATAMENTO ENDODÔNTICO E LIMPEZA INTRA-RADICULAR NA RESISTÊNCIA DE UNIÃO DE PINOS ANATÔMICOS À DENTINA UTILIZANDO CIMENTAÇÃO AUTO-ADESIVA.

BRASÍLIA, 2016 UNIVERSIDADE DE BRASÍLIA 
PROGRAMA DE PÓS-GRADUAÇÃO EM CIÊNCIAS DA SAÚDE

MELISSA MORAIS DE CASTRO GONÇALVES

\section{INFLUÊNCIA DOS AGENTES IRRIGANTES, TEMPO PÓS-TRATAMENTO ENDODÔNTICO E LIMPEZA INTRA-RADICULAR NA RESISTÊNCIA DE UNIÃO DE PINOS ANATÔMICOS À DENTINA UTILIZANDO \\ CIMENTAÇÃO AUTO-ADESIVA.}

Dissertação apresentada como requisito parcial para a obtenção do Título de Mestre em Ciências da Saúde pelo Programa de Pós-Graduação em Ciências da Saúde da Universidade de Brasília.

Orientadora: Ana Paula Dias Ribeiro

BRASÍLIA

2016

MELISSA MORAIS DE CASTRO GONÇALVES 


\section{INFLUÊNCIA DOS AGENTES IRRIGANTES, TEMPO PÓS-TRATAMENTO ENDODÔNTICO E LIMPEZA INTRA-RADICULAR NA RESISTÊNCIA DE UNIÃO DE PINOS ANATÔMICOS À DENTINA UTILIZANDO CIMENTAÇÃO AUTO-ADESIVA.}

Dissertação apresentada como requisito parcial para a obtenção do Título de Mestre em Ciências da Saúde pelo Programa de Pós-Graduação em Ciências da Saúde da Universidade de Brasília.

Aprovado em:

BANCA EXAMINADORA

Prof $^{a}$ Dr $^{\text {a }}$. Ana Paula Dias Ribeiro (Presidente da Banca)

Universidade de Brasília

Prof ${ }^{\mathrm{a}}$ Dra . Patrícia Nóbrega Rodrigues Pereira

Universidade de Brasília

Prof $^{\circ}$ Dro $^{\circ}$. Celso de Freitas Pedrosa Filho (Profo Convidado)

Universidade de Brasília

Prof $^{\circ}$ Dro‥ Leandro Augusto Hilgert (Suplente)

Universidade de Brasília 
Dedico este trabalho ao meu companheiro de vida, Henrique... 


\section{AGRADECIMENTOS}

Gratidão a Deus e à espiritualidade maior que me conduziu amorosamente até aqui!

Em 2009 conheci a Professora Dra. Patrícia Nóbrega Rodrigues Pereira, lembro-me como se fosse hoje! Assisti a uma aula dela sábado o dia todo, sem horário de almoço e, nem eu ou os demais alunos ali presentes, vimos o tempo passar ou sentimos cansaço. Estávamos todos extasiados com seu brilhantismo, generosidade e simplicidade ímpares.

Anos de contatos esporádicos e em 2014 num sábado de manhã vim à Brasília encontrá-la em companhia de minha amiga-irmã Tatiana Clementino. Nesse dia constatei não existir o acaso e minha vida transformou-se de forma indelével. Uma vida nova, inesperada, repleta de desafios que me fizeram crescer e enxergar-me com outras cores.

Obrigada Pat por sua benção que me transformou numa pessoa mais inteira e presente.

Obrigada por ter me apresentado à Professora Dra. Ana Paula Dias Ribeiro, que me acolheu e tornou-se minha âncora com sua disponibilidade, parceria, conhecimento e dinamismo.

Sou grata, vocês tornaram-se para mim espelhos. Admiro e honro a mulher, a mãe, a profissional e as pesquisadoras que vivem dentro de vocês e me inspiram.

Agradeço também minha família que mesmo distante se faz presente, especialmente minha mãe Sara pela torcida, apoio e orações, mesmo não entendendo muitas vezes minhas ansiedades e falta de tempo.

Agradeço à família do Henrique - meu marido - que sempre me apoiou apesar das minhas escolhas resultarem em ausência.

A todos professores que me orientaram nas disciplinas que cursei neste programa de pós-graduação, em especial aos demais mestres do departamento de Dentística, Leandro e Fernanda.

Ao professor e amigo lussif Mamede Neto da Universidade Federal de Goiás por sua preciosa colaboração e disponibilidade, inclusive nos feriados. 
Às amigas queridas, Lívia, Luísa, Alessandra e Marília que dividiram comigo os altos e baixos dessa caminhada que nos fez crescer e sorrir.

A aluna de iniciação científica Amanda Wobido pela troca que existiu entre nós, pelo acolhimento junto à sua família, pelas "mesmas manias" em busca da metodologia, dos termos e formatações apropriadas, pela maturidade nas tomadas de decisões, enfim, pela amizade.

As ex-alunas e alunas de pós-graduação Ana Luísa Laguardia, Daniella Leal Vieira, Débora Lousan, Jéssica Araújo, Josy Lorena Peres, Júlia Cohen e Nicole Aimé, que conheci nos primeiros dias de aula e se tornaram pessoas queridas e sempre presentes.

Aos técnicos do LABMIC - Goiânia, Henrique e Tatiane, obrigado pela atenção e profissionalismo.

A Edgréss sempre atenciosa em todas as solicitações.

A Dona Marly imagem forte e serena, obrigada pela certeza de que viver é o mais importante.

Por fim, sou eternamente grata a todas as pessoas que se envolveram de alguma forma na realização deste sonho nascido no dia 08 de janeiro de 2000 - dia da minha colação de grau - e realizado nesta data, também inesquecível, 21 de julho de 2016. 
"O que conta é a luz que cada um tenha conseguido fazer brilhar em si mesmo".

(Chico Xavier) 


\section{RESUMO}

O objetivo deste trabalho foi investigar a influência de agentes endodônticos irrigantes, tempo pós-tratamento endodôntico e método de limpeza após a desobturação na resistência de união $(R U)$ de pinos anatômicos à dentina utilizando cimentação autoadesiva por meio de teste micro push-out. Oitenta raízes de incisivos bovinos foram endodônticamente tratadas com diferentes soluções irrigadoras e obturados com cimento AH PLUS e guta-percha. As raízes foram divididas em 10 grupos com 8 espécimes cada, dentre os quais existiu três variáveis: (1) a solução irrigadora, (2) dois intervalos de tempos distintos entre a finalização da endodontia e cimentação dos pinos anatômicos e (3) solução irrigadora usada após a desobturação endodôntica e previamente a cimentação autoadesiva dos grupos 1 e 2 subdivididos em A e B de acordo com a solução usada. Os grupos ficaram distribuídos da seguinte maneira: grupos imediatos (de números ímpares)- G1A, NaCL 0,9\% e limpeza com água destilada; G1B, NaCL 0,9\% e limpeza com álcool; G3, clorexidina 2,\% (CHX); G5, hipoclorito de sódio 2,5\% (NaOCL); G7, hipoclorito de sódio 5,25\% (NaOCL); grupos 7 dias (de números pares)- G2A, NaCL 0,9\% e limpeza com água destilada; G2A, NaCL 0,9\% e limpeza com álcool; G4, clorexidina 2\% (CHX); G6, hipoclorito de sódio 2,5\% (NaOCL) e G8, hipoclorito de sódio 5,25\% (NaOCL). Os pinos anatomizados com resina composta foram cimentados com cimento autoadesivo imediatamente ou 7 dias após a desobturação endodôntica. Após 7 dias de armazenamento, as raízes foram seccionadas transversalmente em slices de $1 \mathrm{~mm}$, submetidas ao teste de micro push-out e os modos de fratura foram classificados. Os valores de RU obtidos em Mpa (Megapascal) de todos os grupos foram submetidos ao teste de Análise de Variância a dois critérios complementado pelo teste de Tukey $(\alpha=0,05)$. O modo de fratura mista foi predominante em todos os grupos. Na análise dos fatores solução irrigadora e tempo, foram observadas diferenças significativas apenas em relação ao fator tempo, sendo que a comparação entre os tempos de cimentação imediata e após 7 dias demonstrou que os valores de RU foram superiores para o tempo de 7 dias $(p<0,00001)$. Foram também observadas diferenças significativas em relação ao fator limpeza, tempo e interação entre eles, sendo que os grupos submetidos a limpeza com álcool absoluto apresentaram valores superiores 
aqueles submetidos a limpeza com água destilada apenas para o período de 7 dias. Diante das limitações do presente estudo, foi possível observar que o tempo de espera para desobturação do conduto radicular e cimentação do pino influenciou diretamente os valores de resistência de união de pinos anatomizados cimentados com cimento autoadesivo à dentina. Em relação às soluções irrigadoras, não houve diferença entre clorexidina, hipoclorito e soro fisiológico, de forma que quando se utiliza um protocolo único de desobturação (água destilada), o possível efeito residual das soluções irrigantes é anulado. A solução de limpeza do conduto radicular após a desobturação também influenciou os valores de $\mathrm{RU}$, sendo que o álcool resultou em valores superiores para o período de 7 dias.

Palavras-chave: Cimentos Resinosos; Pino de Fibra; Resistência de União; Hipoclorito de Sódio; Clorexidina; Cimento Endodôntico. 


\section{ABSTRACT}

The aim of this study was to investigate the influence of endodontic irrigation solutions, endodontic post filling timing and dentin cleaning method before post cementation in the bond strength (BS) of anatomical posts cemented with self-adhesive cement through microshear test (push-out). Eighty bovine incisors roots were endodontically treated with different irrigation solutions and filled with $\mathrm{AH}$ Plus and gutta-percha. The roots were divided into 10 groups of 8 specimens each, of which existed three variables: (1) irrigation solution, (2) two different intervals between the end of endodontics and cementation of anatomical pins and (3) dentin cleaning method before cementation. The self-adhesive cementation of groups 1 and 2 were divided into A and B according to the cleaner (distilated water or absolute alcohol). The groups were divided as follows: immediate groups (odd numbers) - $\mathrm{G} 1$ : $\mathrm{NaCl} 0.9 \%$ and cleaning with distilled water; $\mathrm{G} 1 \mathrm{~B}$ : $\mathrm{NaCl} 0.9 \%$ and cleaning with alcohol; G3: chlorhexidine 2\% (CHX); G5: 2.5\% sodium hypochlorite ( $\mathrm{NaOCl}$ ); G7: 5.25\% sodium hypochlorite (NaOCl); Groups 7 days (even numbers) - G2A: $\mathrm{NaCl} 0.9 \%$ and cleaning with distilled water; $\mathrm{G} 2 \mathrm{~A}$ : $\mathrm{NaCl} 0.9 \%$ and cleaning with alcohol; G4: $2 \%$ chlorhexidine $(\mathrm{CHX})$; G6: $2.5 \%$ sodium hypochlorite $(\mathrm{NaOCl})$ and $\mathrm{G} 8: 5.25 \%$ sodium hypochlorite $(\mathrm{NaOCl})$. The anatomical posts were cemented with self-adhesive cement immediately or 7 days after endodontic removal procedure. After 7 days of storage, slices of $1 \mathrm{~mm}$ were obtained and subjected to the push-out test. The BS values obtained in Mpa (Megapascal) of all groups were submitted to analysis of variance test two criteria complemented by Tukey test $(\alpha=0.05)$ and the fracture modes were classified. The mixed fracture mode was predominantly in all groups. In the analysis of irrigant and time factors, significant differences were observed only in relation to time, and the comparison between the immediate cementation time and after 7 days showed that the BS values were higher for the time of 7 days $(p<0.00001)$. Significant differences were also observed in relation to cleaning method, time and their interaction, and the groups subjected to cleaning with absolute alcohol presented higher values than those subjected to cleaning with distilled water only for the 7-days period. Beyond the limitations of this study, it was observed that the waiting time for post cementation influenced the BS values of anatomical posts cemented with self-adhesive cement. Regarding irrigation solutions, there was no difference between chlorhexidine, 
hypochlorite and saline, so that when using a single cleaning protocol (distilled water) is used, the possible residual effect of irrigation solutions is canceled. The cleaning method of the root canal before post cementation also influenced the BS values, and the alcohol resulted in higher values for 7 -days period

Keywords: Resin Cements; Fiber Post; Bond Strength; Sodium Hypochlorite; Chlorhexidine; Endodontic Sealer. 


\section{LISTA DE FIGURAS}

Figura 1 - Imagem de um dos espécimes selecionados.

Pág 11

Figura 2 - Sequência de reembasamento do pino de fibra de vidro com resina composta.

Figura 3 - llustração do corte dos slices e representação da

plataforma do teste de push-out

Pág 18

Figura 4 - Linha do tempo da metodologia.

Pág 19

Figura 5 - Microscópio Eletrônico de Varredura (MEV), Jeol, JSM 6610, equipado com EDS, Thermo scientific NSS Spectral Imaging.

Pág 20

Figura 6 - Espécimes desidratados, cortados e metalizados dispostos em stub para MEV.

Pág 21

Figuras 7A, 7B - Imagens obtidas pela MEV/ Grupo NaCL IMD.

Pág 23

Figuras 8 A, 8 B - Imagens obtidas pela MEV/ Grupo NaCL 7 dias.

Pág 24

Figuras 9 A, 9 B - Imagens obtidas pela MEV/ Grupo CHX IMD.

Pág 24

Figuras 10 A, 10 B - Imagens obtidas pela MEV/ Grupo CHX 7 dias.

Pág 24

Figuras 11 A, 11 B - Imagens obtidas pela MEV/ Grupo NaOCL 2,5\% IMD.

Pág 25

Figuras 12 A, 12 B - Imagens obtidas pela MEV/ Grupo NaOCL 2,5\% 7 dias.

Pág 25

Figuras 13 A, 13 B - Imagens obtidas pela MEV/ Grupo NaOCL 5,25\% IMD.

Pág 25

Figuras 14 A, 14 B - Imagens obtidas pela MEV/ Grupo NaOCL 5,25\% 7 dias.

Pág 25

Figuras 15 A, 15 B-Vista superior dos slices após submetidos ao teste push-out, exemplos de fraturas mistas.

Pág 27

Figuras 16 A, 16 B - Vista superior dos slices após submetidos ao teste push-out, exemplos de fraturas coesivas.

Pág 27

Figuras 17 A, 17 B, 17 C - Imagens obtidas pela MEV do terço médio das raízes que tiveram desobturação imediata (0-4h) e limpeza com água.

Pág 28 
Figuras 18 A, 18 B, 18 C - Imagens obtidas pela MEV do terço médio das raízes que tiveram desobturação imediata (0-4h) e limpeza com álcool absoluto.

Pág 28

Figuras 19 A, 19 B, 19 C - Imagens obtidas pela MEV do terço apical das raízes que tiveram desobturação imediata (0-4h) e limpeza com água, em três magnificações diferentes.

Pág 28

Figuras 20 A, 20 B, 20 C - Imagens obtidas pela MEV do terço apical das raízes que tiveram desobturação imediata (0-4h) e limpeza com álcool absoluto, em três magnificações diferentes.

Pág 28

Figuras 21 A, 21 B, 21 C - Imagens obtidas pela MEV do terço médio das raízes que tiveram desobturação após 7 dias e limpeza com água, em três magnificações diferentes.

Pág 29

Figuras 22 A, 22 B, 22 C - Imagens obtidas pela MEV do terço médio das raízes que tiveram desobturação após 7 dias e limpeza com álcool absoluto, em três magnificações diferentes.

Pág 29

Figuras 23 A, 23 B, 23 C - Imagens obtidas pela MEV do terço apical das raízes que tiveram desobturação após 7 dias e limpeza com água, em três magnificações diferentes.

Pág 29

Figuras 24 A, 24 B, 24 C - Imagens obtidas pela MEV do terço apical das raízes que tiveram desobturação após 7 dias e limpeza com álcool absoluto, em três magnificações diferentes.

Pág 29 


\section{LISTA DE TABELAS}

Tabela 1 - Distribuição dos grupos de acordo com a solução irrigadora utilizada, intervalo de tempo para cimentação do pino de fibra de vidro e irrigação prévia a cimentação autoadesiva.

Pág 12

Tabela 2 - Materiais usados, composição química, lote/fabricante. Pág 13

Tabela 3 - Médias (desvio padrão) para resistência de união por meio de teste push-out, em MPa, nos diferentes terços radiculares.

Pág 22

Tabela 4 - Resultado da ANOVA a dois fatores (solução irrigadora e tempo) para resistência de união à dentina de pinos anatomizados.

Pág 22

Tabela 5 - Médias (desvio padrão) para resistência de união por meio de teste push-out, em MPa, nos diferentes grupos experimentais.

Pág 23

Tabela 6 - Resultado da ANOVA a dois fatores (protocolo de limpeza e tempo) para resistência de união à dentina de pinos anatomizados. Pág 26

Tabela 7 - Resultado da ANOVA a dois fatores (protocolo de limpeza e tempo) para resistência de união à dentina de pinos anatomizados. Pág 26

Tabela 8 - Classificação e distribuição das fraturas. 


\section{LISTA DE ABREVIATURAS E SIGLAS}

$\mathrm{CHX}$ - Clorexidina

EDTA - Àcido etilenodiamino tetra-acético

IMD - imediato

$\mathrm{N}$ - Newton

$\mathrm{NaCL}$ - Cloreto de sódio

$\mathrm{NaOCL}$ - Hipoclorito de sódio

MPA - Megapascal

MMP - Matriz metaloproteinases

$\mathrm{RU}$ - Resistência de União 


\section{SUMÁRIO}

$\begin{array}{ll}\text { 1. INTRODUÇÃO } & \text { Pág } 01\end{array}$

2. OBJETIVOS Pág 10

3. METODOLOGIA Pág 11

3.1 PREPARAÇÃO DOS ESPÉCIMES Pág 11

3.2 PREPARAÇÃO INTRA-CANAL PARA CIMENTAÇÃO DOS PINOS ANATÔMICOS Pág 13

REEMBASAMENTO DOS PINOS DE FIBRA DE VIDRO COM RESINA COMPOSTA

Pág 14

3.4 CIMENTAÇÃO INTRA-CANAL DO PINO ANATÔMICO Pág 14

3.5 PUSH-OUT Pág 17

3.6 MICROSCOPIA ELETRÔNICA DE VARREDURA Pág 20

3.7ANÁLISE ESTATÍSTICA Pág 21

4. RESULTADOS Pág 22

5. DISCUSSÃO Pág 30

6. CONCLUSÃO Pág 35

7. REFERÊNCIAS BIBLIOGRÁFICAS Pág 36 


\section{INTRODUÇÃO}

Dentes tratados endodônticamente diferem de elementos dentais vitais (1) principalmente por apresentarem em sua maioria, perda de estrutura coronal $(2,3,4)$ resultantes de lesões cariosas $(4,5,6,7)$, fraturas (7), acesso endodôntico incorreto $(2,6)$ instrumentação excessiva $(3,4)$, substituições de restaurações prévias (7), reabsorções internas (8) e malformações ligadas à traumatismos $(5,8)$. Consequentemente, a perda de estruturas histológicas como a dentina (5) e anatômicas como cúspides, cristas marginais e câmara pulpar (5) fragilizam a estrutura comprometendo suas propriedades físicas e, às vezes, aparência estética $(1,8)$. Por estas razões requerem uma abordagem restauradora complexa (9) e especializada (5). Entretanto, as características e quantidade precárias do remanescente coronário $(1,2,3,10,11,12,13)$ induzem, na maioria dos casos, à utilização de pinos intrarradiculares $(2,4,13,14)$ à fim de prover retenção adequada das restaurações finais $(4,11)$ diretas ou indiretas $(7)$.

Requisitos de resistência de união e estética (9) guiam a restauração de um dente tratado endodônticamente. $\mathrm{O}$ objetivo é transferir as tensões de maneira biomecanicamente favorável desde a raiz até a restauração coronária e estrutura dental remanescente (12). Contudo, deve-se ter em mente que a principal função de um pino intrarradicular não é o reforço físico do dente tratado endodônticamente, mas a retenção e estabilidade à longo prazo da restauração coronária $(5,11)$. Assim, a compatibilidade entre os diferentes materiais utilizados no tratamento de canal e a cimentação de pinos intrarradiculares na dentina radicular é um aspecto importante a ser considerado para um tratamento restaurador bem-sucedido (7).

Tradicionalmente pinos e restaurações metálicas sempre foram a principal opção de tratamento para dentes tratados endodônticamente $(1,14)$. Em geral, esses pinos metálicos eram compostos de materiais de alto módulo de elasticidade (14) como ouro, aço inoxidável ou dióxido de zircônia $(3,15)$ e retidos ao conduto radicular mecanicamente (6) por meio da cimentação com cimento de fosfato de zinco ou de ionômero de vidro (14). No entanto, discussões polêmicas os levaram ao desuso devido à grande variedade de desvantagens a eles associadas, como por exemplo o aumento do risco de fratura radicular vertical $(1,5,15)$ - possuem maior dureza 
comparada à da dentina (15), problemas de corrosão associados às ligas metálicas (15), radiopacidade em relação aos dentes naturais (5) e risco de perfuração radicular durante sua remoção (5).

Em um contexto contemporâneo, a utilização de pinos de fibra de vidro é um procedimento aceito (6) e têm sido a opção de escolha pelos clínicos por suas inúmeras vantagens: são biocompatíveis $(11,16)$, apresentam modo de elasticidade próximo ao da dentina $(3,4,9,10,12,16,17,18)$ e por isso formam com o remanescente coronário uma unidade mecanicamente homogênea $(3,9,19)$, capaz de absorver e distribuir favoravelmente as tensões geradas pelas forças mastigatórias $(3,4,9,12)$, protegendo o remanescente radicular do risco de fraturas severas $(1,10,12,18)$. Ainda são econômicos (19), reduzem o tempo de conclusão do tratamento endodôntico/protético (9), resistentes a corrosão $(5,16)$ e de aparência estética (5) com nenhum risco de escurecimento gengival ou alteração da superfície radicular (5), especialmente na região anterior (5).

Pinos de fibra podem ser classificados de acordo com sua concepção (préfabricados padrão ou individualizados em diversas formas, diâmetro e tamanho), ou de acordo com seu tipo de matriz polimérica (reticulado ou IPN - interpenetrando matriz polimérica rede de polímero) (19). Ainda contém fibras de reforço que podem ser de carbono, quartzo, ou de vidro embebidas em matriz epóxica ou de resina metacrilata polimerizada (15). As ligações interfaciais entre a fibra e a matriz resultam em melhores propriedades mecânicas (19) e a disposição paralelas das fibras podem atuar como um guia para os instrumentos rotatórios, facilitando sua remoção, se necessário, no caso de uma revisão endodôntica ou depois de uma fratura (5).

Em canais amplos, com paredes radiculares delgadas (1), nos quais o espaço entre as paredes do canal radicular e o pino é maior; têm sido largamente difundidos $(3,4)$ o uso de pinos de fibra de vidro reembasados com resina composta (1). Esta técnica é conhecida por anatomização de pinos ou mesmo pinos anatômicos $(1,2,3,4,20)$. O objetivo dessa técnica é modelar o conduto radicular, individualizandoo (1), com finalidade de melhorar a adaptação do pino de fibra de vidro, reduzir a linha de cimentação, e reforçar as paredes radiculares com resina composta que atua, nestes casos, como dentina artificial (1). Gomes et al (14) em 2014 testaram cinco alternativas restauradoras em canais amplos: (1) controle negativo- pino de fibra menor que o canal radicular, (2) pino de fibra com pinos acessórios, (3) restauração interna das paredes radiculares com resina composta, (4) pinos anatômicos diretos e 
(5) pinos anatômicos indiretos. Após a cimentação de coroas indiretas esses espécimes foram submetidos à fadiga ( $1.2 \times 106$ cycles, $40 \mathrm{~N})$ e, posteriormente, parte deles submetidos a testes de push-out BS test e outros a RF teste (resistência à fratura). O teste RF apresentou resultado similar em todos os grupos, no entanto, os resultados do teste de push-out mostrou que somente as técnicas de pino anatômico direto e indireto foram similares ao grupo controle positivo- diâmetro do pino de fibra compatível com o endodonto; indicando serem as melhores alternativas restauradoras para canais amplos.

As vantagens dos pinos de fibra em relação aos metálicos são muitas, destacando-se o fato de permitirem cimentação adesiva $(1,16)$, embora a adesão à dentina radicular seja complexa (10) e de durabilidade duvidosa (16). Alguns estudos indicam resultados longitudinais positivos (9) e que vão ao encontro a importância de uma união confiável nas interfaces $(2,13,20)$ dentina/ cimento resinoso/ pino de fibra, que garanta o equilíbrio biomecânico desse monobloco (3) e a longevidade do procedimento restaurador (12). Entretanto, a cimentação adesiva de pinos de fibra de vidro deve ser considerada um complexo procedimento adesivo, pois seu sucesso depende da interação de aspectos únicos da dentina radicular, tais como a orientação e densidade dos túbulos dentinários nas diferentes porções da raiz além das inúmeras variáveis que envolvem desde o início do procedimento endodôntico até a escolha da estratégia adesiva (22). Ainda deve ser considerado, conhecimento e comunicação dos cirurgiões - dentistas especialistas em endodontia e dentística restauradora acerca de todos aspectos relacionados aos procedimentos executados.

Dentre as possíveis variáveis, as soluções irrigantes endodônticas representam uma etapa essencial na preparação mecânica das paredes do conduto (6) e são capazes de alterar a superfície dentinária interferindo na interação com materiais adesivos (8,23). O hipoclorito de sódio ( $\mathrm{NaOCl})$, em diferentes concentrações (23), tem sido amplamente utilizado por sua excelente atividade antimicrobiana $(1,2,20,21)$ e capacidade de dissolução de debris orgânicos $(6,8,19,21,23)$. A clorexidina (CHX) mostra ação antimicrobiana $(1,2,20,21)$ tão efetiva quanto a do hipoclorito de sódio (NaOCl) (8), entretanto é inábil na remoção de tecidos necróticos remanescentes (21). Se nesse aspecto- da atividade antimicrobiana, podem ser equiparadas, em relação a ação no tecido dentinário apresentam ações opostas. Enquanto o $\mathrm{NaOCl}$ altera os componentes orgânicos da dentina, especialmente o colágeno $(6,8,23)$, devido à sua ação desproteinizante inespecífica (13); a CHX é conhecida por aumentar a 
longevidade da camada híbrida, pela inibição da matriz metaloproteinases (MMPs) $(1,2,13,16,19,20)$.

As MMPs $(2,20)$ são proteínas não-colagenosas presentes na dentina coronária e radicular $(2,20)$ que permitem através da afinidade desse substrato à água (5) penetração de umidade na camada híbrida $(2,5,20)$ e consequentemente hidrólise das fibrilas de colágeno expostas $(1,2,20,16)$ durante o condicionamento ácido e não hibridizadas pelos monômeros adesivos (1). Consequentemente, ocorre aceleração da degradação de toda interface adesiva por meio dessa indiscriminada atividade hidrolítica e estratégias que visem inibição dessa atividade é de grande interesse, pois a maioria das falhas clínicas ocorrem devido a desunião destes pinos à dentina radicular ao longo do tempo $(4,16)$.

Além das soluções irrigantes, os materiais adesivos também vêm sendo modificados a fim de permitir uma adesão mais favorável e longeva. Uma dessas mudanças relacionou-se ao uso de solventes como etanol e acetona que fossem capazes de ligar-se à agua residual $(1,2,20)$ contida no interior da dentina condicionada. Numa outra abordagem focada em eliminar o condicionamento ácido, surgiu a proposição de um sistema de adesivo auto condicionante (22) com monômeros acídicos, os quais, simultaneamente, desmineralizam e se infiltram na camada de smear layer e na dentina subjacente, eliminando o colapso das fibras colágenas e, consequentemente, possíveis falhas no procedimento adesivo e melhorando, desta forma, a união entre pino e dentina radicular (22). E por último, os cimentos resinosos autoadesivos que ganharam popularidade em relação aos sistemas de múltiplos passos $(16,17)$ por não requererem pré-tratamento das superfícies dentais (5). Sua aplicação simplificada, em único passo clínico $(10,25)$, diminui a vulnerabilidade da hibridização dentinária (13) e maximiza a resistência de união sem comprometer a estabilidade das interfaces dentina/cimento resinoso/pino de fibra anatômico $(13,15,16)$.

Por enquanto não existe um consenso na literatura sobre qual solução endodôntica oferece maiores vantagens ou mesmo desvantagens em relação à adesão a dentina radicular e suas interações frente aos diferentes sistemas adesivos e agentes de cimentação. Em 2011 um trabalho de pesquisa realizado por Cecchin et al (2) diferentes pré-tratamentos da dentina radicular bovina foram testados após condicionamento com ácido fosfórico utilizando clorexidina gel $2 \%$, álcool $100 \%$ e a combinação de ambos seguidos de irrigação com solução salina ( $\mathrm{NaCL}$ ), previamente 
a cimentação de pinos anatômicos com cimento resinoso dual; e concluiu após $24 \mathrm{~h}$ de armazenamento e teste push-out, que todos protocolos empregados não interferiram na resistência de união imediata. Em outra publicação (1), o mesmo grupo de pesquisadores utilizou a mesma metodologia no preparo dos espécimes variando apenas o tempo de armazenamento - 24 h e 12 meses, e obtiveram resultados que indicaram que o pré-tratamento com clorexidina manteve a resistência de união ao final de 12 meses. Por outro lado, Leitune et al (13) em 2010 avaliaram a influência da clorexidina $0,2 \%$ ou 2,0\% na resistência de união imediata e após 6 meses de pinos de fibra cimentados em dentina radicular humana após condicionamento ácido, aplicação de sistema adesivo de 3 passos e cimento resinoso dual. Concluíram que após 6 meses, a aplicação de clorexidina não deteve efetivamente a degradação da resistência de união dos pinos de fibra cimentados em raízes humanos.

Outros trabalhos em dentes humanos também avaliaram a ação da clorexidina, ZHOU et al (16) em 2013 observaram a durabilidade da interface adesiva combinando clorexidina e ED PRIMER, adesivo auto-condicionante. Formulações experimentais, nas quais, diferentes quantidades de clorexidina $20 \%$ foram adicionadas ao ED PRIMER originando misturas com três concentrações de clorexidina $(0 \%, 0.5 \%$ e 1.0\%). O ED PRIMER é um auto-condicionante de único passo apresentado comercialmente em 02 frascos, líquido $A$ e líquido $B$, misturados em quantidades iguais e usados em conjunto com o cimento resinoso dual PANAVIA $F$, ambos do mesmo fabricante, KURARAY. O teste push-out foi realizado após 24 h e 18 meses de armazenamento e concluiu que a adição de clorexidina 1\% no ED PRIMER pode estender a longevidade da união de pinos de fibra à dentina.

Lindblad (19) et al em 2010 também analisaram o efeito da clorexidina na proservação da adesão, associando-a a dois sistemas adesivos de condicionamento ácido total e um cimento autoadesivo. Neste trabalho, realizado com dentes humanos, três marcas de pinos de fibra de vidro cimentados usando as três estratégias adesivas acima mencionadas; nos grupos em que foi realizado condicionamento com ácido fosfórico a 37\% durante 15 segundos na dentina radicular, após sua lavagem seguiuse irrigação com clorexidina $2 \%$ por $1 \mathrm{~min}$, aplicação do sistema adesivo e cimentos resinosos dos mesmos fabricantes. Naqueles grupos em que cimento autoadesivo foi utilizado, neste caso, Rely-x Unicem (3M/ESPE), a irrigação foi feita com solução salina estéril. $O$ tempo de armazenamento foi de 3 - 7 dias a fim de permitir presa 
completa dos cimentos. Neste estudo conclui-se que a clorexidina não afetou negativamente a resistência de união do pino avaliada por meio de push-out.

Uma outra solução irrigadora, o hipoclorito de sódio, sozinho ou seguido de solução de EDTA (23) (ácido etilenodiamino tetra-acético) como irrigante final (8), também têm sido frequentemente utilizadas com o propósito de desmineralizar a dentina e promover adequada limpeza da camada de esfregaço formada durante instrumentação endodôntica e/ou desobturação do endodonto. Este protocolo tem sido justificado, pois com as paredes radiculares mais limpas e livres de restos orgânicos e inorgânicos os tags dentários tornam-se mais suscetíveis à penetração de substâncias químicas e ao contato apropriado com cimento obturador endodôntico ou cimento resinoso (8). Isto, apesar do EDTA também alterar as propriedades físico químicas da dentina (23) assim como o hipoclorito de sódio.

Investigando esses irrigantes endodônticos, Moreira (23) em 2009 avaliou o efeito do hipoclorito de sódio a 5.25\%, EDTA 17\%, CHX gel 2\% e cloreto de sódio 0.9\% (NaCL) sobre a matriz dentinária de dentes bovinos. Após instrumentação endodôntica todas as amostras foram preenchidas com as substâncias químicas auxiliares respectivas de seus grupos. Após $48 \mathrm{~h}$ cortadas pela metade, uma metade foi submetida a MEV e outra a PLM, uma técnica de descalcificação realizada em um período de 3 a 5 semanas. Concluiu-se que $\mathrm{NaOCI} 5,25 \%$ associado ou não ao EDTA $17 \%$ causa alterações no colágeno da dentina. As imagens da microscopia de varredura também mostraram que os grupos que usaram EDTA $17 \%$, isolado ou associado a outras substâncias, tiveram áreas desmineralizadas.

$\mathrm{Na}$ mesma linha desse trabalho, Jardim et al (24) em 2014 avaliaram a influência de soluções irrigadoras isoladas ou em combinação com EDTA previamente a cimentação de pinos de fibra com o cimento autoadesivo Rely-x Unicem (3M/ESPE), são elas: (1) NaCL 0.9\% (controle); (2) hipoclorito de sódio 5.25\%, (3) hipoclorito de sódio + EDTA 17\%, (4) clorexidina gel 2\% e (5) clorexidina gel 2\% + EDTA17\%. Os resultados sugeriram que a clorexidina gel $2 \%$ com ou sem irrigação final com EDTA promove condições mais favoráveis a cimentação com cimento autoadesivo que o hipoclorito de sódio a 5,25\%.

Em 2014 Stevens (25) avaliou a resistência imediata ao cisalhamento de diferentes categorias de cimentos resinosos em dentina humana tratadas com $\mathrm{NaOCL}$ $6 \%$ através da imersão dos espécimes durante 20 min e subsequente tratamento com ascorbato de sódio durante 5 segundos e 1 minuto nos grupos que tiveram forças de 
união diminuída para dentina. Cinco cimentos foram testados: Variolink II (Ivoclair Vivadent), Multilink (Ivoclair Vivadent), Clearfil Esthetic Semente EX (Kuraray), SpeedCEM (Ivoclair Vivadent), e Clearfil SA Cimento (Kuraray). Todos os cimentos foram testados com e sem pré-tratamento de $\mathrm{NaOCl}$ a dentina (controle negativo). Concluiu que os cimentos resinosos variam em sua capacidade a aderir a dentina tratada com $\mathrm{NaOCL}$, alguns exibem resistência de união igual ou melhorada, entretanto outros apresentaram diminuição significante, restaurada em até $50 \%$ dos valores de união inicial após lavagem com ascorbato de sódio 10\%. Observa-se, portanto, que a literatura apresenta ainda muitas divergências em relação às soluções irrigantes endodônticas de forma que não há um consenso sobre o efeito das mesmas em relação a adesão à dentina radicular e suas interações com as diversas estratégias adesivas disponíveis.

Ainda em relação ao tratamento endodôntico, o tipo de cimento obturador assim como o tempo de espera para desobturação do canal e limpeza desse conduto após a desobturação são fatores que podem interferir na adesão. Cimentos endodônticos são tão influentes na perda de retenção do pino como a forma de cimentação escolhida (11). Cimentos à base de resina epóxica são preferidos devido às suas boas propriedades físicas e desempenho biológico adequado. Os baseados em hidróxido de cálcio podem estimular um fechamento biológico da região apical, aumentando assim de sucesso do tratamento cimentos, entretanto, os que contém eugenol continuam a ser o cimento endodôntico mais comumente usados por causa de sua longa história de sucesso clínico (11). Apesar disso, o eugenol, como todos os fenóis, tem consideráveis propriedades de eliminação de radicais, e este é pensado para inibir a polimerização da resina composta (11). Há pouco consenso entre os estudos sobre se essa interação é clinicamente relevante e não está claro se a presença de eugenol e outros componentes dos cimentos endodônticos, restos de tecido pulpar, e / ou uma camada de esfregaço residual podem prejudicar a retenção do pino (11).

Em 2013 quatro publicações abordaram esse aspecto e utilizaram teste pushout como meio de avaliação da resistência de união. Rosa et al (9) analisaram em raízes bovinas a influência do tipo de cimento obturador endodôntico e o intervalo para cimentação do pino de fibra após obturação do endodonto. Os seguintes cimentos endodônticos foram usados: AH PLUS baseado em resina epóxica e sem eugenol, Endofill baseado em eugenol e MTA baseado em MTA Fillapex; em dois intervalos de tempo entre as etapas de desobturação/ cimentação do pino, imediato ou 15 dias após 
conclusão da endodontia. Após a desobturação o conduto preparado para o pino foi irrigado com água destilada. Um percentual de $89,4 \%$ das falhas foi adesiva e na interface dentina/cimento resinoso dual ALL CEM (FGM) e as seguintes conclusões foram elaboradas: o intervalo entre desobturação/ cimentação do pino não influenciou a adesão entre pino e dentina, o tipo de cimento endodôntico pode influenciar a adesão e após 15 dias o cimento baseado em resina epóxica obteve os maiores de resistência de união entre pino e dentina.

Ainda em espécimes bovinos obturados com Sealer-26 (Dentsply Caulk, Milford, USA) Faria-e-Silva et al (10) em 2013 testaram as seguintes soluções após desobturação dos condutos: ácido poliacrílico $11.5 \%$ durante 30 segundos, EDTA $17 \% / 60$ segundos, $5 \% \mathrm{NaOCl} / 60$ segundos e água destilada no grupo controle, previamente a cimentação de pinos de fibra de vidro com dois cimentos autoadesivos BisCem (Bisco) e Rely X Unicem clicker (3M/ESPE). O teste push-out foi realizado 7 dias após a cimentação e os resultados apontaram que as soluções usadas no experimento podem interferir com a retenção de pino de fibra.

No mesmo ano, em espécimes humanos $K$ AlEisa et al (11) analisaram dois cimentos baseados em eugenol - Endofill (Dentsply) e TubliSeal (KERR), e AH 26 (Dentsply), baseado em resina epóxica. Após a desobturação o conduto preparado para o pino foi irrigado com hipoclorito de sódio $5,25 \%$ seguido de água destilada. Os espécimes em que $\mathrm{AH} 26$ foram usados exibiram os maiores valores de união em relação aos cimentos baseados em eugenol.

Num outro estudo, Bitter et al (21) após instrumentação e obturação com AH PLUS (Dentsply DeTrey, Konstanz, Germany) de cento e cinquenta espécimes de dentes humanos, investigaram o efeito de cinco protocolos de irrigação distintos, realizados após a desobturação do conduto e combinados com três estratégias adesivas: um sistema adesivo auto-condicionante - Adhese DC com MultiCore Flow (Ivoclair Vivadent, Schaan, Liechtenstein), um sistema de 3 passos - XP Bond e Self Cure Activator com Core X Flow (Dentsply DeTrey, Konstanz, Germany) e um cimento autoadesivo - SmartCem2 (Dentsply DeTrey). Os protocolos de irrigação foram; IP1 (controle) - $5 \mathrm{ml}$ água destilada; IP2- hipoclorito de sódio ( $\mathrm{NaOCl}$ ) 5.25\% com irrigação ultrassônica; IP3-1\% NaOCl com irrigação ultrassônica, IP4- (EDTA) 18\% seguido por $\mathrm{NaOCl} 5.25 \%$ e IP5- clorexidina 2\%. A irrigação com EDTA $18 \%$ seguido por $\mathrm{NaOCl}$ $5,25 \%$ aumentou a resistência de união do cimento resinoso autoadesivo e diminuiu os valores do sistema adesivo de 3 passos comparando com o controle, enquanto 
NaOCL 1\% melhorou a resistência de união deste sistema adesivo, ou seja, cada estratégia adesiva deve ser adaptada a um específico protocolo de irrigação prévio à cimentação de pinos de fibra.

Coincidentemente ou não, assim como ocorre com clorexidina, hipoclorito de sódio e EDTA, muitas discussões pairam sobre cimentos endodônticos que contém ou não eugenol e seus efeitos na interface adesiva dentina/cimento resinoso/pino de fibra de vidro. Os trabalhos que os avaliam são de metodologia mais complexa pois, reproduzem IN VITRO além da instrumentação dos condutos radiculares, sua obturação com guta-percha e cimento obturador e posterior desobturação e preparo para cimentação do pino de fibra.

Enfim, ainda há muitos questionamentos acerca da ação das soluções endodônticas na cimentação autoadesiva, melhor intervalo de tempo para realizar desobturação do conduto radicular e método de limpeza mais apropriado desse conduto previamente a cimentação adesiva. Desafios estes que precisam ser estudados numa lógica eficiente, que aproxime e interligue pesquisa e a dinâmica diária da clínica odontológica à fim de respostas que tragam mais consistência e segurança em relação aos protocolos que podem ou não dar certo e que, ao mesmo tempo, proporcione menor tempo clínico, protocolos de trabalhos otimizados e prognóstico favorável. 


\section{OBJETIVOS}

Desta forma o objetivo do presente estudo foi avaliar a influência dos agentes irrigantes, tempo pós-tratamento endodôntico e limpeza intrarradicular durante a desobturação do conduto radicular na resistência de união de pinos anatômicos à dentina utilizando cimentação autoadesivo. As seguintes hipóteses nulas foram testadas: 1) não existe efeito residual das diversas soluções irrigadoras utilizadas no tratamento endodôntico assim como interferência das mesmas na resistência de união de pinos anatômicos cimentados com cimento autoadesivo à dentina; 2) o tempo pós obturação endodôntica não influencia na resistência de união de pinos anatômicos cimentados com cimento autoadesivo à dentina; 3) a limpeza do conduto radicular após desobturação endodôntica com água ou álcool não influencia na resistência de união de pinos anatômicos cimentados com cimento autoadesivo à dentina. 


\section{METODOLOGIA}

\subsection{PREPARAÇÃO DOS ESPÉCIMES.}

Foram selecionados de 150 incisivos bovinos recém extraídos, oitenta espécimes com tamanho e formato semelhantes e com ápices completamente formados (figura 1). À fim de padronizar os condutos radiculares usamos lima $\mathrm{K} \# 30$ como patência. Os dentes foram estocados em solução de timol a 10\% por no máximo 4 meses. Os tecidos moles foram removidos com curetas periodontais e estando limpos os dentes ficaram armazenados em água destilada. Todos os dentes tiveram suas coroas cortadas perpendicularmente $1 \mathrm{~mm}$ abaixo da junção amelocementária com um disco diamantado refrigerado à água em velocidade lenta. As raízes foram cortadas em um tamanho uniforme de $16 \mathrm{~mm}$ de comprimento.

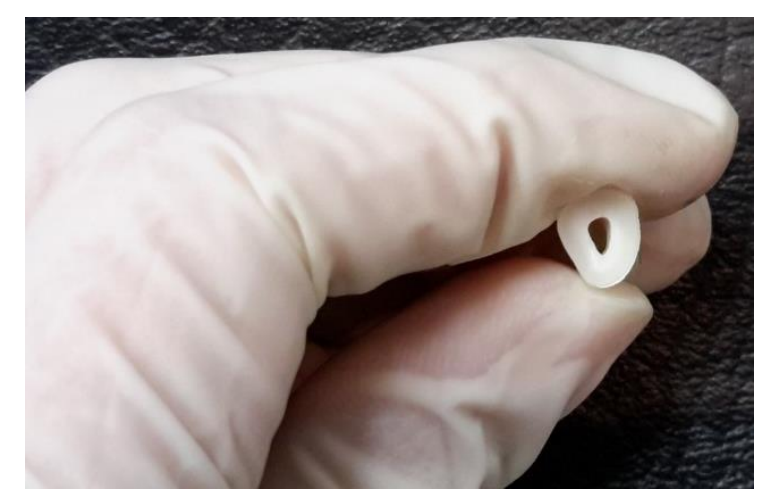

Figura 1: Imagem de um dos espécimes selecionados.

Os canais radiculares foram instrumentados por um mesmo operador treinado. A instrumentação foi realizada pela técnica "step back" $(6,9,10,17)$, utilizando limas Kfile \#30 a \#80 e brocas Gates-Glidden \#2 e \#3. Removeu-se todo o tecido pulpar e os canais foram alargados estabelecendo uma lima mestra $\mathrm{K} \# 50$ como padrão. Os canais foram preparados $1 \mathrm{~mm}$ aquém do comprimento total da raiz $(15 \mathrm{~mm})$ para evitar extravasamento de cimento. Durante a instrumentação utilizou-se cada instrumento durante 1 minuto e a cada troca de instrumental o canal radicular foi irrigado com $5 \mathrm{ml}$ das soluções de hipoclorito de sódio (2,5\% e 5,25\%), clorexidina (2\%) ou de soro fisiológico em pressão constante e igual para todos os espécimes. As raízes foram randomicamente distribuídas em 10 (dez) grupos com 8 (oito) espécimes cada, dentre 
os quais existiu três variáveis: (1) a solução irrigadora, (2) dois intervalos de tempo distintos entre a finalização da endodontia e cimentação dos pinos anatômicos e (3) solução irrigadora usada após desobturação endodôntica e previamente a cimentação autoadesiva, no caso dos grupos 1 e 2, grupos controles, subdivididos em A e B de acordo com a solução usada, conforme apresentado na Tabela 1. Os pinos foram anatomizados utilizando pinos de fibra de vidro WhitePost DC №1 (FGM) reembasados com resina Filtek Z-350 XT (3M-ESPE). Para cimentação dos mesmos utilizou-se o cimento resinoso U-200 Clicker (3M-ESPE), inserido no canal com espiral de lentulo rotatório com controle de velocidade para evitar aquecimento do cimento.

Tabela1 - Distribuição dos grupos de acordo com a solução irrigadora utilizada, intervalo de tempo para cimentação do pino de fibra de vidro e irrigação prévia a cimentação autoadesiva.

\begin{tabular}{|c|c|c|c|c|}
\hline $\begin{array}{l}\text { INTERVALO DE } \\
\text { TEMPO }\end{array}$ & GRUPOS & $\begin{array}{l}\text { NUMERO } \\
\text { AMOSTRAL }\end{array}$ & $\begin{array}{c}\text { SOLUÇAO IRRIGADORA } \\
\text { ENDODONTICA }\end{array}$ & $\begin{array}{l}\text { LIMPEZA APÓS DESOBTURAÇÃO/ } \\
\text { CIMENTAÇAOAO AUTOADESIVA }\end{array}$ \\
\hline \multirow{5}{*}{$\begin{array}{l}\text { GRUPOS IMEDIATOS } \\
0-4 \text { HS } \\
\text { DE SOBTURACGAO } \\
\text { DO CONDUTOI } \\
\text { CIMENTACAO AUTOADE SIVA } \\
\text { DO PINO ANATOMICO }\end{array}$} & G1A & 8 & \multirow{2}{*}{ Solução salina $0,9 \%(\mathrm{NaCL})$} & Agua destilada \\
\hline & G1B & 8 & & ALCOOL \\
\hline & G3 & 8 & Clorexidina $2 \%(\mathrm{CHX})$ & Agua destilada \\
\hline & G5 & 8 & Hipoclorito de sódio $2,5 \%$ ( $\mathrm{NaOCL}$ ) & Agua destilada \\
\hline & G7 & 8 & Hipoclorito de sódio $5,25 \%$ ( $\mathrm{NaOCL})$ & Agua destilada \\
\hline \multirow{5}{*}{$\begin{array}{c}\text { GRUPOS } 7 \text { DIAS } \\
7 \text { DIAS } \\
\text { DESOBTURAÇAO } \\
\text { DO CONDUTO } \\
\text { CIMENTCAOAUTOADE SIVA } \\
\text { DO PINO ANATOMICO }\end{array}$} & G2A & 8 & \multirow{2}{*}{ Solução salina $0,9 \%$ ( $\mathrm{NaCL})$} & Agua destilada \\
\hline & $G 2 B$ & 8 & & ALCOOL \\
\hline & G4 & 8 & Clorexidina $2 \%(\mathrm{CHX})$ & Agua destilada \\
\hline & G6 & 8 & Hipoclorito de sódio 2,5\% (NaOCL) & Agua destilada \\
\hline & G8 & 8 & Hipoclorito de sódio $5,25 \%(\mathrm{NaOCL})$ & Agua destilada \\
\hline
\end{tabular}

Após a instrumentação endodôntica, os canais foram secos com pontas de papel absorvente e obturados pela técnica de condensação lateral e vertical. Nesta etapa, foi utilizado cone principal de guta-percha (Dentsply, Petrópolis, RJ, Brasil) correspondente ao último instrumento do preparo apical dos canais e cones acessórios MF e FM, também de guta-percha (Dentsply, Petrópolis, RJ, Brasil), espaçador digital número 2 (Malleifer, Switzerland) e cimento AH PLUS (Dentsply, De Trey GmbH D-78467 Konstanz). 
Tabela 2 - Materiais usados, composição química, lote/fabricante.

\begin{tabular}{|c|c|c|}
\hline MATERIAL & COMPOSIÇÄO QUIMICA & LOTE / FABRICANTE \\
\hline $\begin{array}{l}\text { SISTEMA ADESIVO } \\
\text { SCOTCHBOND MULTIPURPOSE }\end{array}$ & $\begin{array}{l}\text { Bis Glicidilmetacrilato (Bis-GMA), } \\
\text { 2-Hidroxietilmetacrilato (HEMA) e componentes } \\
\text { iniciadores. }\end{array}$ & N721539 / 3M- ESPE \\
\hline RELY-X CERAMIC PRIMER & $\begin{array}{l}\text { Alcool etílico, água, } \\
\text { metacriloxipropiltrimetoxisilane. }\end{array}$ & N699035 / 3M - ESPE \\
\hline RELY-X U-200 & $\begin{array}{l}\text { Pasta base: } \\
\text { monômeros metacrilatos com grupos ácidos, } \\
\text { monômeros metacrilatos, partículas silanizadas, } \\
\text { componentes iniciadores e estabilizadores. } \\
\text { Pasta catalizadora: } \\
\text { monômeros metacrilatos, partículas alcalinas, } \\
\text { partículas silanizadas, componentes iniciadores }\end{array}$ & 586057 / 3M - ESPE \\
\hline FILTEK Z350 XT & $\begin{array}{l}\text { Cerâmica silanizada, sílica tratada com silano, } \\
\text { diuretano dimetacrilato (UDMA), bisfenol A } \\
\text { polietileno glicol diéter dimetacrilato, bisfenol A } \\
\text { diglicidil éter dimetacrilato (BisGMA), zircônia } \\
\text { silanizada, polietilenoglicol dimetacrilato, } \\
\text { dimetacrilato de trietilenoglicol (TEGDMA), 2,6-Di- } \\
\text { terc-butil-p-cresol. }\end{array}$ & $\begin{array}{l}1513300281 / \\
3 \mathrm{M}-\mathrm{ESPE}\end{array}$ \\
\hline WHITEPOST & $\begin{array}{l}80 \% \text { fibra de vidro, } 20 \% \text { resina epóxi, carga } \\
\text { inorgânica e promotores de polimerização. }\end{array}$ & 2021FEB / FGM \\
\hline
\end{tabular}

\subsection{PREPARAÇÃO INTRACANAL PARA CIMENTAÇÃO DOS PINOS ANATÔMICOS.}

Para os espécimes em que a obturação e desobturação do conduto/ cimentação do pino anatômico foi realizada imediatamente $(0-4 \mathrm{H})$, o canal radicular foi desobturado com a broca do kit do WhitePost DC \#1 até $11 \mathrm{~mm}$ de profundidade, removendo toda guta-percha até o comprimento determinado, que corresponde a 2/3 do comprimento inicial de trabalho. Até o momento da desobturação foram mantidos em $100 \%$ de umidade a $37^{\circ} \mathrm{C}$ (graus Celsius). Durante a desobturação utilizou-se água destilada como solução irrigante. Após a desobturação, à fim de certificar que todo cimento foi removido das paredes do conduto radicular, uma lima envolta em algodão estéril e embebida em água destilada foi friccionada contra as paredes, nos grupos controle G1B e G2B esse passo foi realizado com a lima envolta em algodão estéril embebidas em álcool absoluto; em seguida, nova irrigação com água destilada 
e secagem com cone de papel absorvente foi realizada indistintamente, em todos os grupos.

Para os grupos 2 A, 2 B, 4, 6 e 8 em que a desobturação do conduto/ cimentação do pino anatômico foi realizada após 7 dias do tratamento endodôntico, a parte cervical das raízes foi selada com material restaurador provisório Coltosol (Coltene, Vigodent S/A Ind. Bras e Com) e armazenados com condutos obturados em $100 \%$ de umidade a $37^{\circ} \mathrm{C}$ (graus Celsius) e depois passaram pelo mesmo processo de desobturação e cimentação do pino anatômico.

\subsection{REEMBASAMENTO DO PINO DE FIBRA COM RESINA COMPOSTA.}

O reembasamento do pino de fibra de vidro $(3,4)$ WhitePost DC \#1 (FGM) foi realizado com a resina Filtek Z-350 XT (3M ESPE), para tanto o pino foi limpo com ácido fosfórico Ultra-etch (Ultradent) durante 30 segundos para remover resíduos, lavado com água destilada e seco com ar comprimido; em seguida com microbrush (FGM) distintos aplicamos agente de ligação silano Primer Ceramic (3M/ESPE) e adesivo (frasco 3) do Sistema Adper Scotchbond Multiuso Plus (3M/ESPE), ambas camadas tiveram o excesso removido com sugador cirúrgico estéril pressurizado em bomba a vácuo e foram fotopolimerizados durante 20 segundos com fotopolimerizador Valo (Ultradent), em seguida, incremento de resina Filtek Z-350 XT (3M) foi condensado junto à toda circunferência do mesmo. Para evitar que a resina ficasse aderida nas paredes radicular foi aplicado no conduto lubrificante hidrossolúvel KY (Jonhson \& Jonhson) (1). O conjunto pino/resina foi então inserido no conduto radicular e fotopolimerizado ainda dentro do canal durante 10 segundos, retirado cuidadosamente e depois novamente fotopolimerizado por mais 20 segundos fora do conduto com o fotopolimerizador Valo (Ultradent). (Figura 2) 
Previamente à cimentação do pino anatômico os canais radiculares foram novamente lavados com água destilada, secos com sugador cirúrgico estéril pressurizado em bomba a vácuo e a região apical checada com uma lima envolta com algodão estéril. Os pinos anatômicos $(3,4)$ - denominação utilizada após reembasamento com resina composta, também foram limpos com ácido fosfórico Ultra-etch (Ultradent) durante 30 segundos, lavados com água destilada, secos com ar comprimido e receberam aplicação através de Microbrush distintos de uma camada do agente de ligação silano Primer Ceramic (3M/ESPE) seguido de adesivo (frasco 3) do Sistema Adper Scotchbond Multiuso Plus (3M/ESPE), ambas camadas tiveram o excesso removido com sugador cirúrgico estéril pressurizado em bomba a vácuo e foram fotopolimerizadas por 20 segundos com fotopolimerizador Valo (Ultradent). $\mathrm{O}$ cimento autoadesivo U-200 (3M/ESPE) foi inserido no interior do canal com espiral lentulo rotatório (Dentsply, Malleifer, Switzerland) e o pino anatômico posicionado. Esperou-se 5 minutos e a polimerização do pino anatômico foi feita durante 20 segundos.
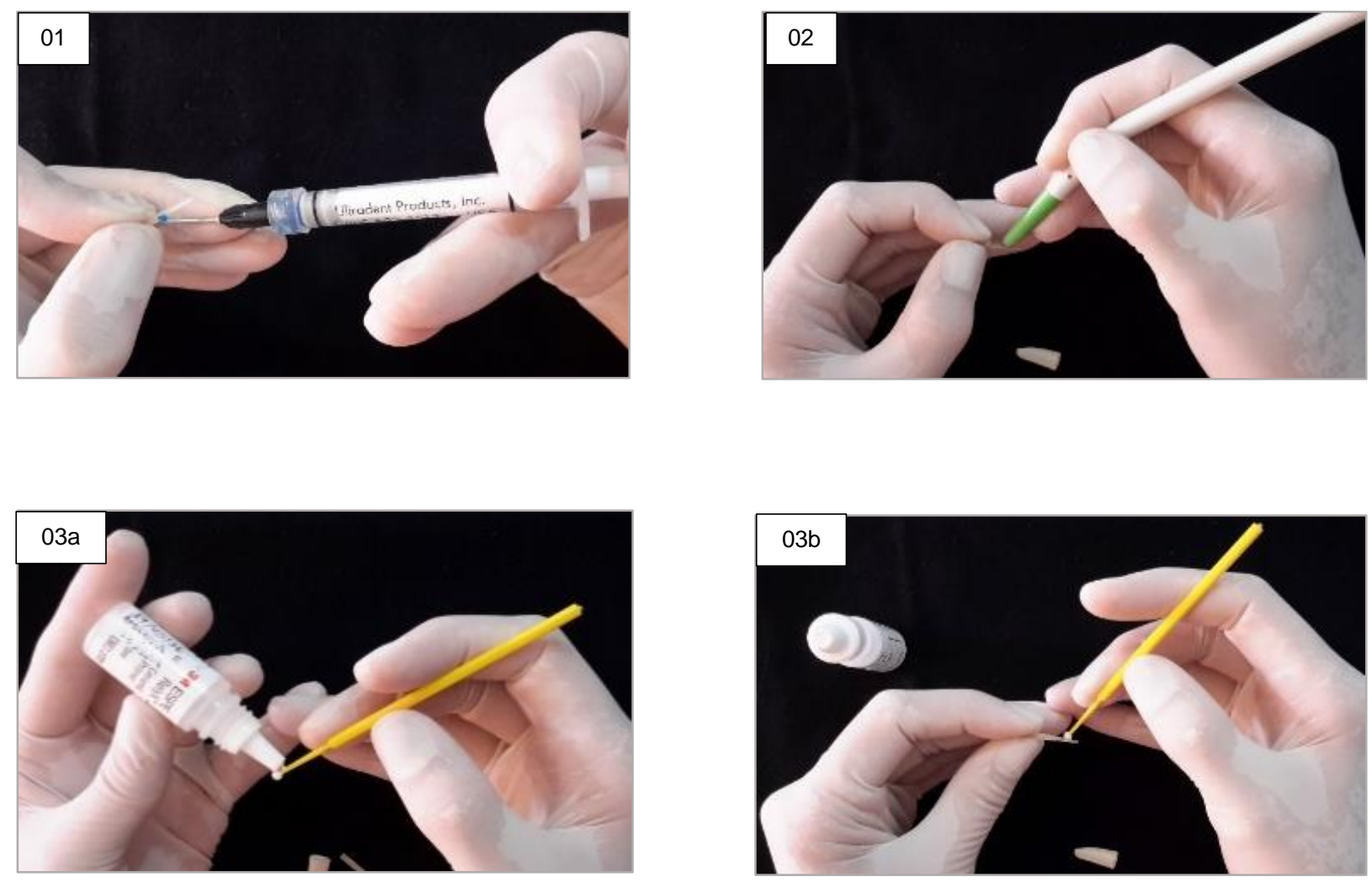

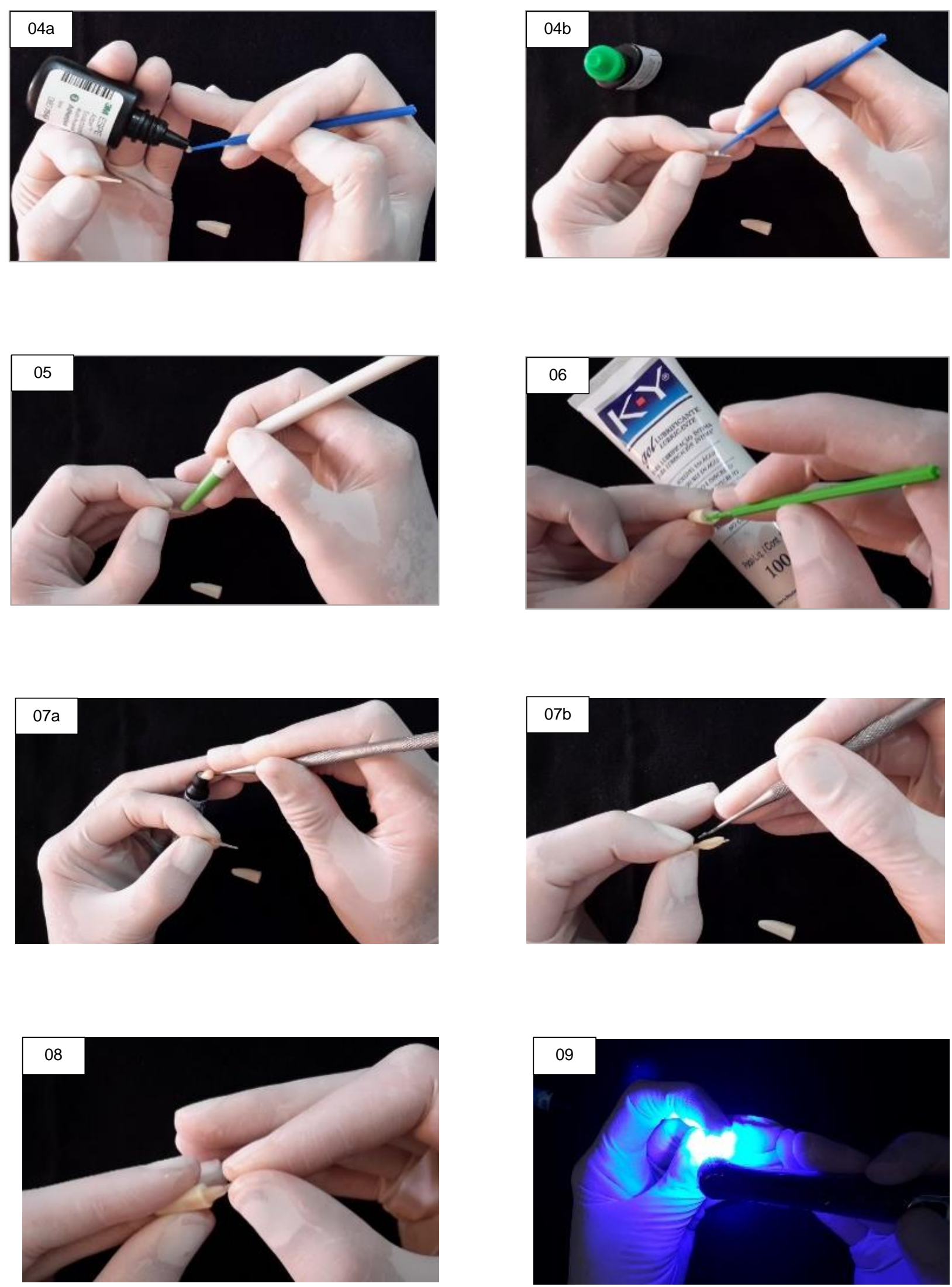

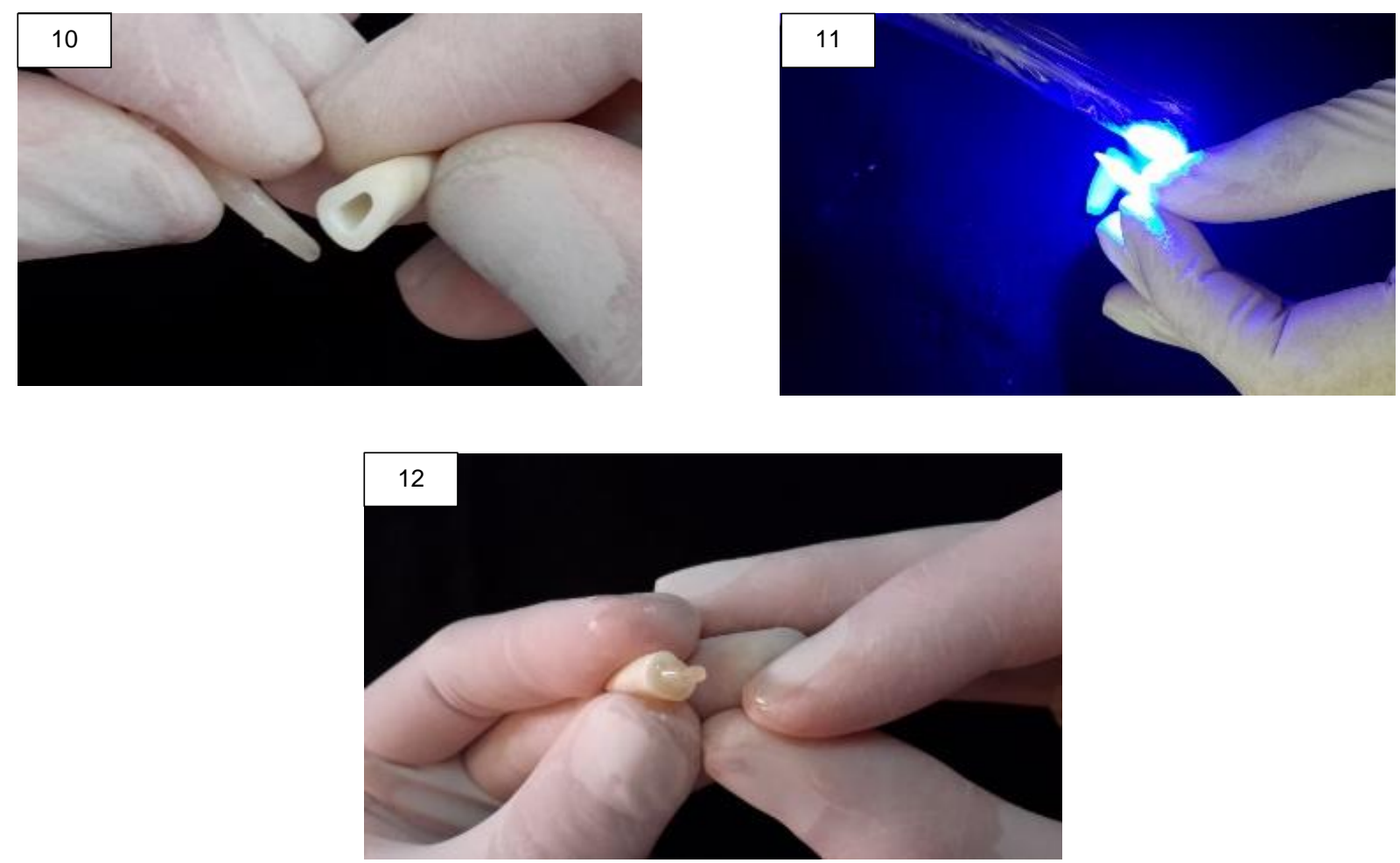

Figura 2 - Sequência de reembasamento do pino de fibra de vidro com resina composta: (01) condicionamento do pino com ácido durante 30 segundos - (02) lavar com água destilada e seco com ar comprimido e sugador cirúrgico estéril pressurizado em bomba a vácuo - (03 a, 03 b) aplicação de silano Rely-x Primer Ceramic (3M/ESPE) - (04 a, 04 b) -aplicação ativa de adesivo (frasco 3) do Sistema Adper Scotchbond Multiuso Plus (3M/ESPE) - (05) excesso de ambas camadas removido com sugador cirúrgico estéril pressurizado em bomba a vácuo e foram fotopolimerizados durante 20 segundos com fotopolimerizador Valo (Ultradent), em seguida, (06) aplicação no conduto de lubrificante hidrossolúvel KY (Jonhson \& Jonhson), (07 a, 07 b) incremento de resina Filtek Z-350 XT (3M) - (08) conjunto pino/resina inserido no conduto radicular e (09) fotopolimerizado ainda dentro do canal durante 10 segundos - (10) retirado cuidadosamente - (11) novamente fotopolimerizado por mais 20 segundos com o fotopolimerizador Valo (Ultradent).

\subsection{TESTE PUSH-OUT.}

Após a cimentação dos pinos anatômicos as raízes foram armazenadas imersas em água destilada a $37^{\circ} \mathrm{C}$ por 07 dias nos grupos $1,3,5,7$ e mais 7 dias nos grupos 2,4,6,8; depois incluídas em blocos de resina epóxica. O conjunto foi seccionado perpendicularmente ao longo eixo da raiz em sete fatias de $1 \mathrm{~mm}$ utilizando-se um disco diamantado na máquina de corte sob refrigeração constante. A primeira fatia foi descartada, restando duas fatias cervicais, duas médias e duas apicais. Cada fatia foi mensurada por um paquímetro digital e todas as secções foram 
submetidas ao teste mecânico micro push-out (12), na habilidade de medir a resistência de união entre pinos de fibra reembasados com resina e dentina radicular.

Realizou-se o teste push-out pela aplicação de uma carga de $0,5 \mathrm{~mm} / \mathrm{min}$ com direção da região apical para a coronal até que o pino anatômico fosse deslocado da fatia da raiz / slice. A ponta da realização do teste foi posicionada no centro do pino de fibra de vidro para todos os espécimes.

Para expressar a força de união em megapascal (MPa), a força foi medida em newton $(\mathrm{N})$ e dividida pela área da interface pino anatômico-dentina $\left(\mathrm{mm}^{2}\right)$. Para calcular a área usamos a fórmula $2 \pi \mathrm{Rh}$, onde $\mathrm{R}$ era o raio medido do centro do pino em direção a parede vestibular e h era a altura (espessura) da fatia. A angulação entre a porção mais apical e a mais cervical foi considerada $0^{\circ}$. Todas as medidas foram feitas utilizando um paquímetro digital.

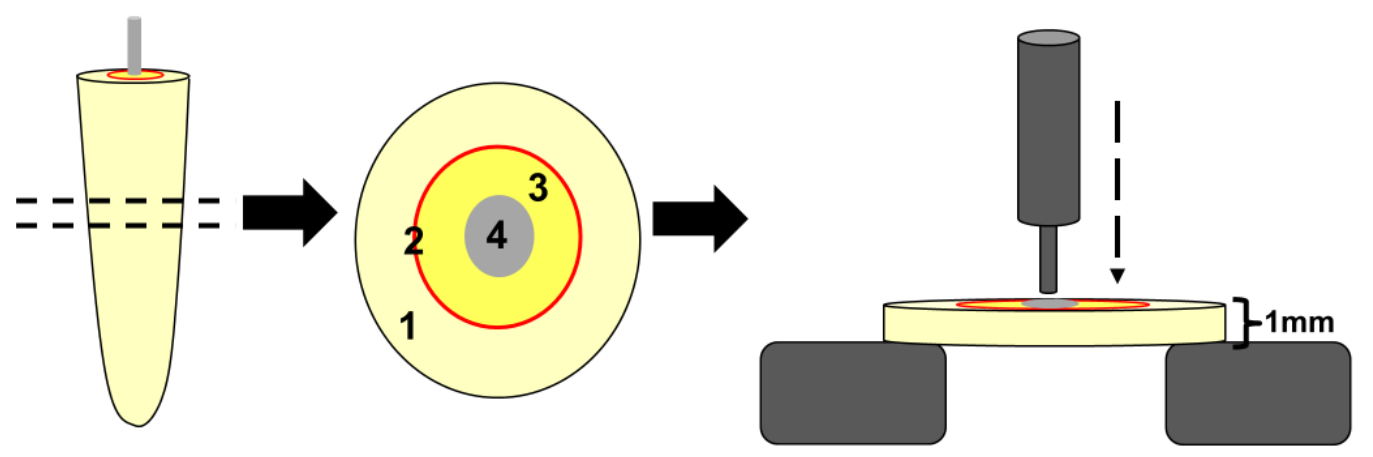

Figura 3 - llustração do corte dos slices e representação da plataforma do teste de push-out.

Após a realização do teste mecânico, os discos foram analisados utilizando uma lupa com aumento de 20X para determinar o padrão de fraturas dos espécimes. A figura 5 apresenta, em forma de linha do tempo, a sequência da metodologia utilizada no presente estudo. 


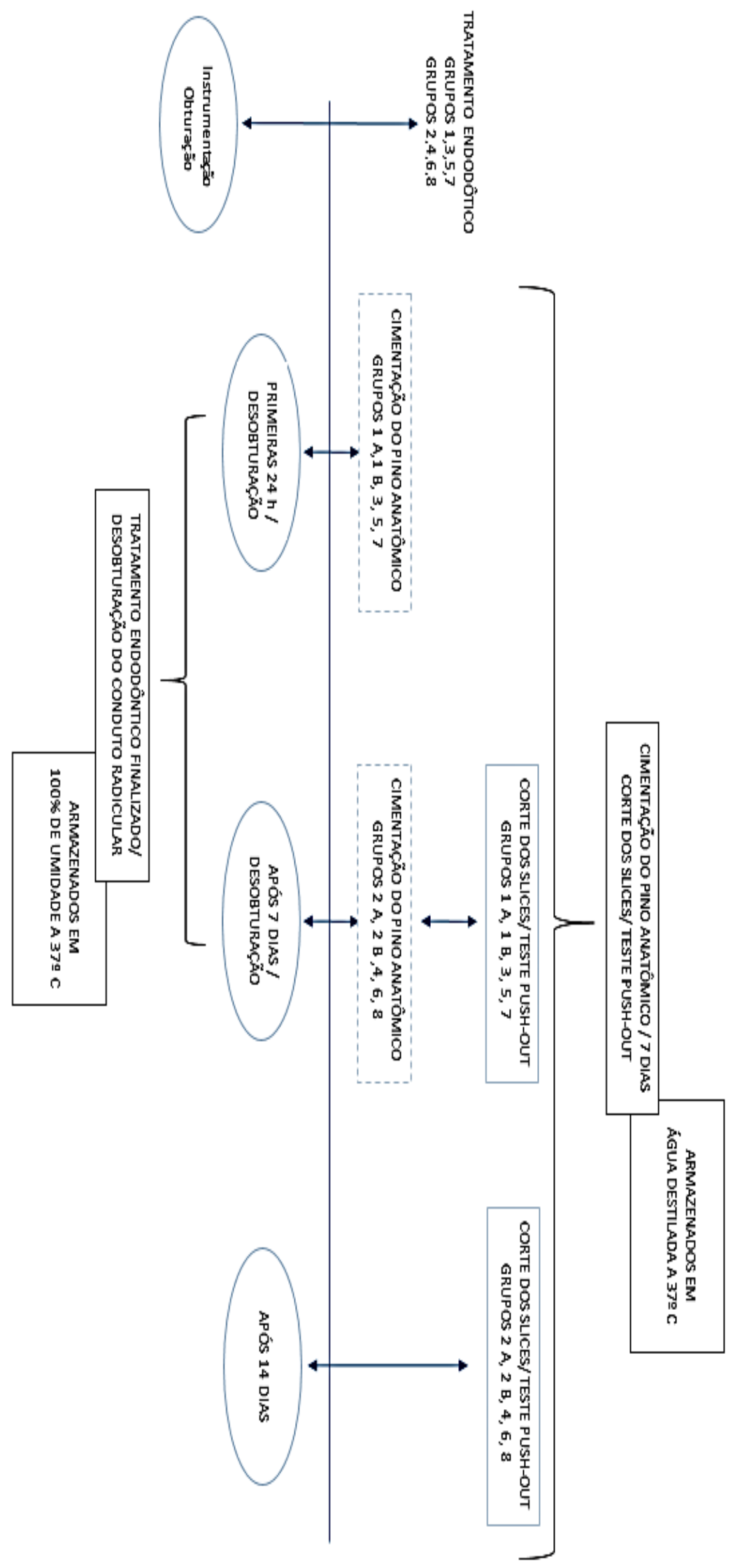

Figura 4 - Linha do tempo da metodologia. 


\subsection{MICROSCOPIA ELETRÔNICA DE VARREDURA (MEV)}

As imagens foram realizadas no Laboratório Multiusuário de Microscopia de Alta Resolução - LABMIC, Goiânia no Microscópio Eletrônico de Varredura (MEV), Jeol, JSM - 6610, equipado com EDS, Thermo scientific NSS Spectral Imaging (figura $5)$.

Para isso, anteriormente, os slices selecionados de acordo com o modo de fratura mais constante foram cortados ao meio e submetidos a um processo de desidratação aumentando a concentração das soluções alcoólicas de forma crescente - 30\%, 50\%, 70\%, 90\%, trocando-as a cada 30 min e depois colocados em ambiente totalmente fechado, com sílica. No LABMIC os espécimes cortados e desidratados foram montados em stubs e metalizados com o sistema para deposição de filmes de ouro, Denton Vacuum, Desk V, equipado com o acessório de carbono. A figura 6 apresenta os espécimes após metalização.

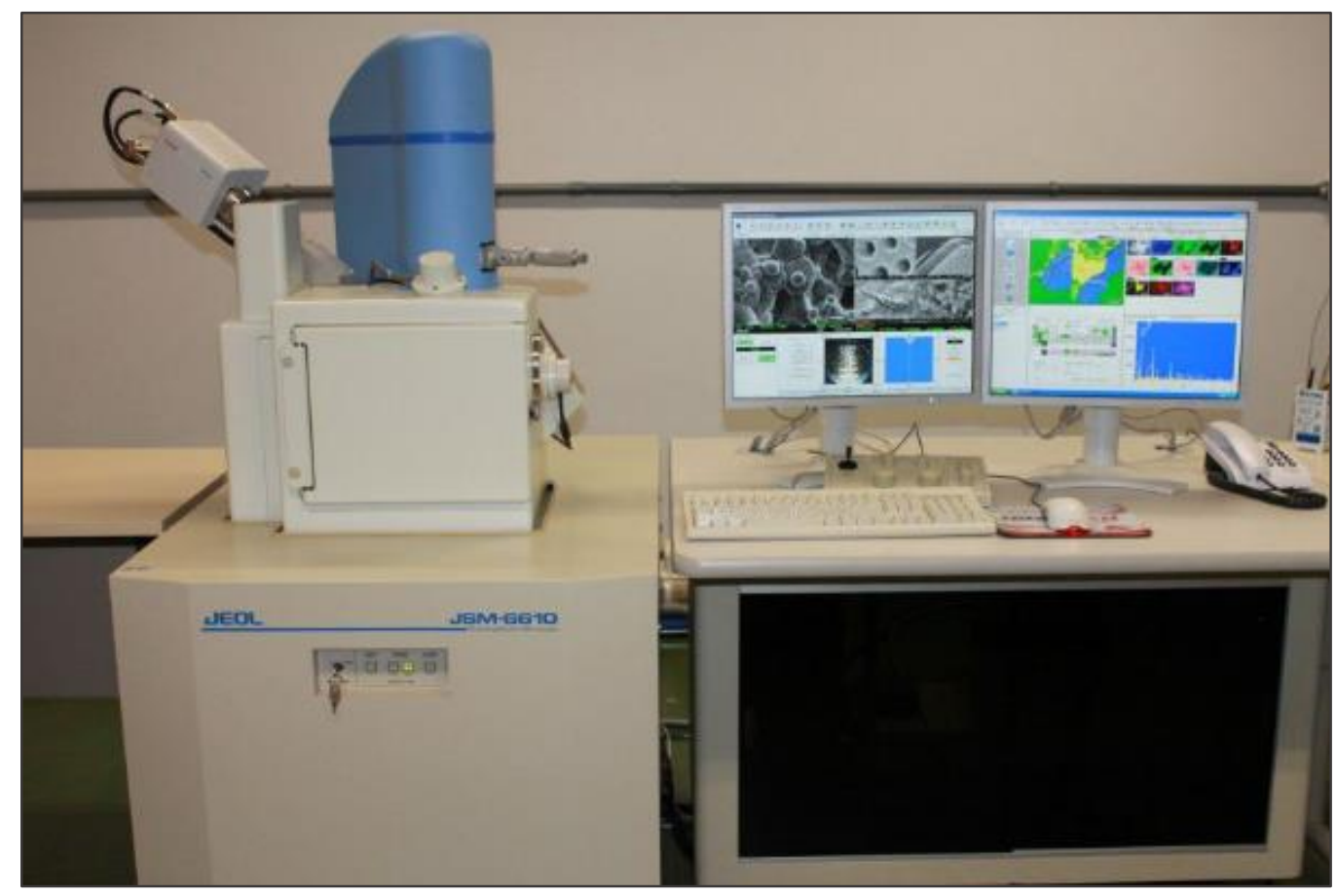

Figura 5 - Microscópio Eletrônico de Varredura (MEV), Jeol, JSM - 6610, equipado com EDS, Thermo scientific NSS Spectral Imaging 


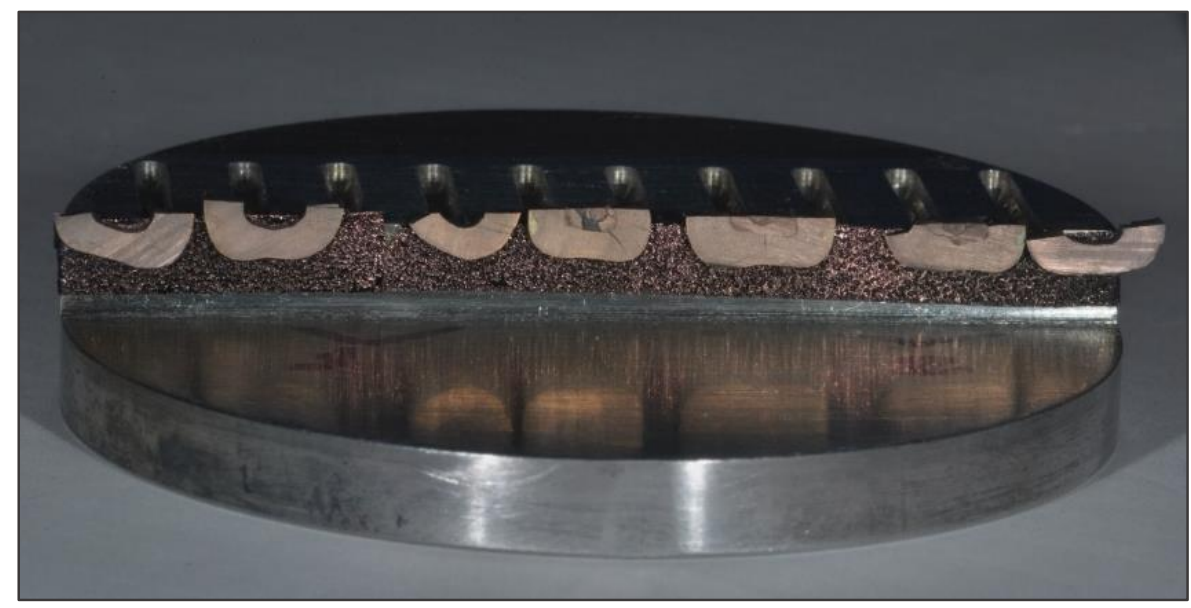

Figura 6- Espécimes desidratados, cortados e metalizados dispostos em stub para MEV.

Cinco espécimes extras, cortados ao meio, após desobturação do conduto com broca do sistema de pino fibra utilizado, foram submetidos à microscopia eletrônica de varredura à fim de obter imagens que tornassem evidentes possíveis diferenças entre os dois diferentes protocolos de limpezas realizados nos grupos controles $G 1 A$, G1B, G2A, G2B.

\subsection{ANÁLISE ESTATÍSTICA.}

Os valores de resistência de união foram calculados em Mpa. Inicialmente, realizou-se uma análise estatística a fim de verificar a presença de diferença estatística entre os slices dos diferentes terços. Uma vez que o valor de $p$ foi $\geq 0,05$, os valores obtidos dos diferentes slices de todos os terços foram incluídos na análise estatística final $(n=48)$. Os dados foram analisados pelo Análise de Variância a dois critérios (solução irrigante $X$ tempo e agente de limpeza $X$ tempo) complementado pelo teste de Tukey com nível de significância de 0.05 . 


\section{RESUltados}

O conjunto de dados de resistência de união $(\mathrm{MPa})$ à dentina dos pinos anatomizados foi submetido a análise de variância a um critério a fim de verificar diferenças estatísticas entre os terços. Na tabela 3 são apresentadas as médias e desvio-padrão dos diferentes terços (apical, médio e cervical). Não foram observadas diferenças entre os terços (one way ANOVA, $p=0.33$ ).

Tabela 3 - Médias (desvio padrão) para resistência de união por meio de teste push-out, em MPa, nos diferentes terços radiculares.

\begin{tabular}{c|c}
\hline Terços & Média (DP) \\
\hline Cervical & $9.90(3.12)$ \\
Médio & $9.26(3.01)$ \\
Apical & $9.67(4.18)$ \\
\hline
\end{tabular}

Em seguida, o conjunto de dados de resistência de união (MPa) à dentina dos pinos anatomizados foi submetido a análise de variância a dois critérios fixos ("tratamento" e "tempo"). Foram observadas diferenças significativas apenas em relação ao fator tempo (Tabela 4).

Tabela 4 - Resultado da ANOVA a dois fatores (solução irrigadora e tempo) para resistência de união à dentina de pinos anatomizados.

\begin{tabular}{l|c|c|c|c}
\hline \multicolumn{1}{c|}{ FATORES } & $\begin{array}{c}\text { GRAU DE } \\
\text { LIBERDADE }\end{array}$ & MS & F & P \\
\hline Tratamento & 3 & 6.5 & 0.63 & 0.59 \\
Tempo & 1 & 298.2 & 28.99 & $0.0000^{\star}$ \\
Tratamento \# Tempo & 3 & 7.9 & 0.77 & 0.51 \\
\hline
\end{tabular}

${ }^{\star}$ Diferenças significativas. 
Dessa forma, a comparação entre os tempos de cimentação 24 horas ou após 7 dias demonstrou que os valores de resistência de união foram superiores para o tempo de 7 dias, sendo o valor de $p<0.00001$. As médias e desvio-padrão da força de união dos diferentes grupos estão representados na Tabela 5. Observa-se que para todos os grupos experimentais, os valores de resistência de união obtidos 24 horas após a cimentação foram inferiores aos valores obtidos no período de 7 dias

Imagens ilustrativas de todos os grupos, em ambos intervalos de tempo, obtidas por MEV estão disponíveis nas figuras: 7A, 7B (grupo controle imediato), 8A, 8B (grupo controle 7 dias), 9A, 9B (grupo $\mathrm{CHX}$ imediato), 10A, 10B (grupo $\mathrm{CHX} 7$ dias), 11A, 11B (grupo NaOCL 2,5\% imediato), 12A, 12B (grupo NaOCL 2,5\% 7dias) 13A, 13B (grupo NaOCL 5,25\% imediato), 14A, 14B (grupo NaOCL 5,25\% 7dias).

Tabela 5 - Médias (desvio padrão) para resistência de união por meio de teste push-out, em MPa, nos diferentes grupos experimentais.

\begin{tabular}{c|c|c}
\hline Solução irrigante & Período de 0-4 horas & Período de 7 dias \\
\hline Soro Fisiológico & $8.36(1.96)$ & $10.47(3.03)$ \\
Clorexidina 2\% & $8.80(3.18)$ & $11.19(2.78)$ \\
Hipoclorito de Sódio 2,5\% & $8.99(3.77)$ & $10.88(3.89)$ \\
Hipoclorito de Sódio 5,25\% & $9.27(3.73)$ & $10.252 .69)$ \\
\hline
\end{tabular}
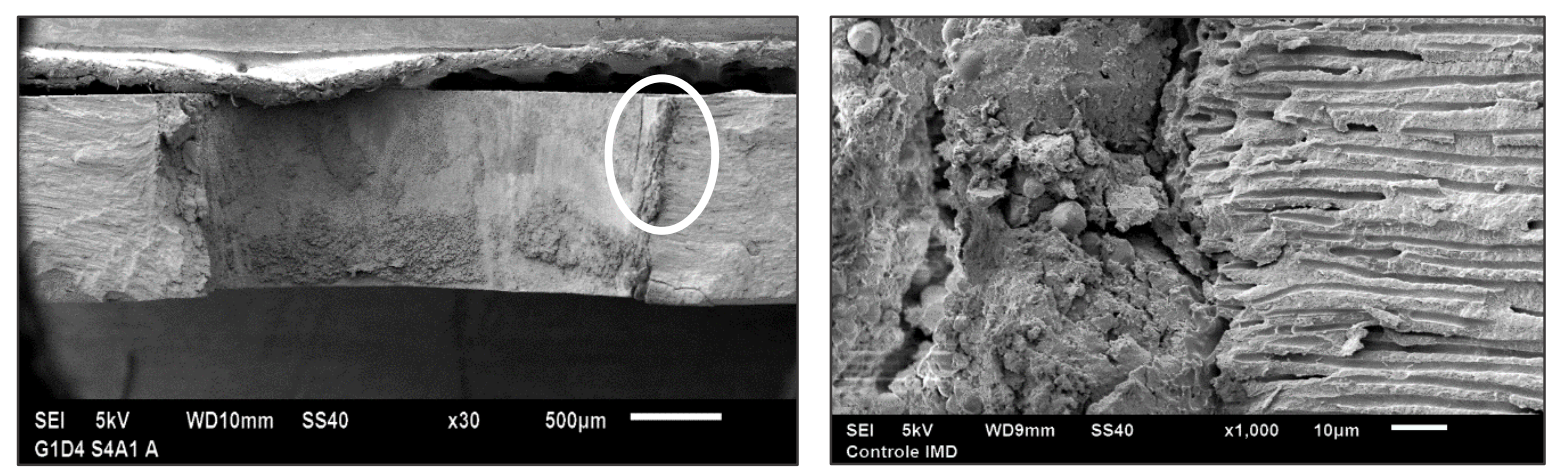

Figuras 7A, 7B - Grupo 1A (NaCL imediato) - vista superior da fratura, assinalado, região em que foi realizado 0 aumento $\times 1000$. Figura $7 \mathrm{~B}$ - nota-se a interface da resina composta com a parede dentinária e fina camada do cimento resinoso autoadesivo U-200. 

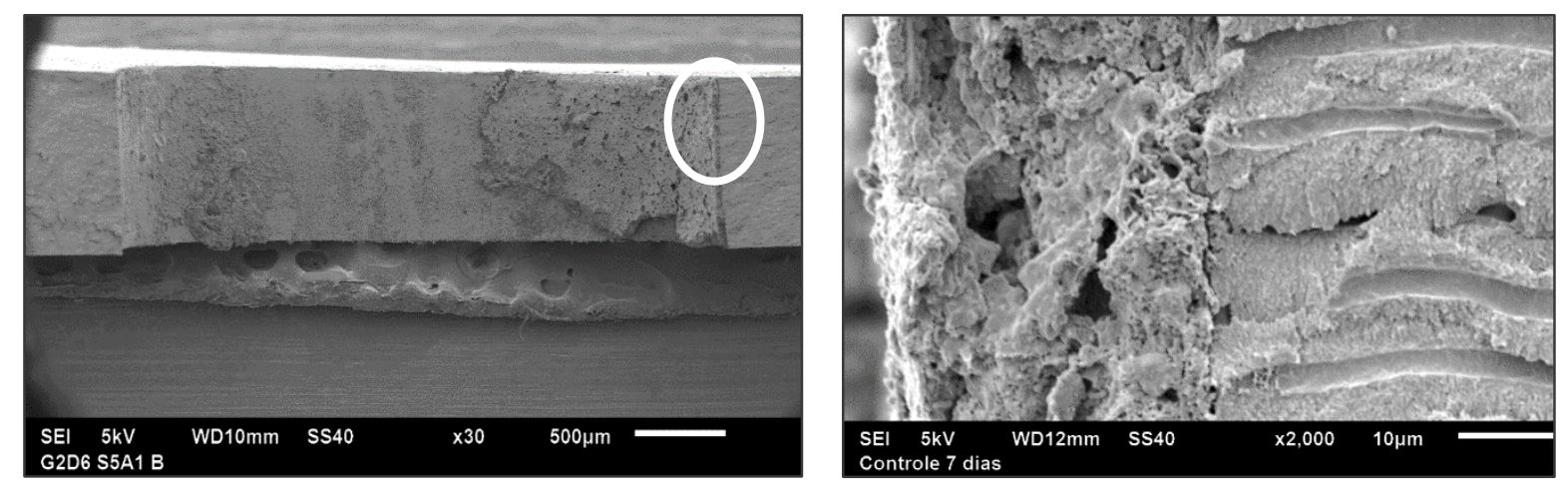

Figuras 8A, 8B - Grupo 2A (NaCL 7dias) - vista superior da fratura, assinalado, região em que foi realizado o aumento $\times 1000$. Figura $8 \mathrm{~B}$ - nota-se camada do cimento resinoso autoadesivo U-200 com a parede dentinária.
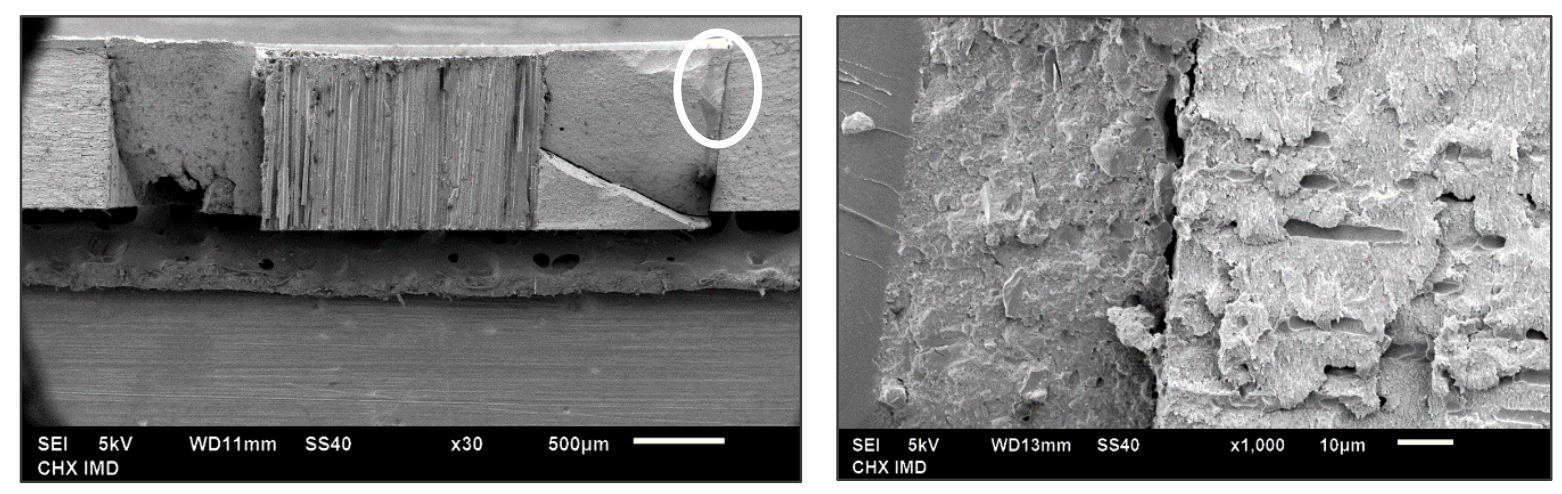

Figuras 9A, 9B - Grupo 3 (CHX 2\% imediato). Figura 9A - vista superior da fratura, assinalado, região em que foi realizado o aumento $\times 1000$. Figura $9 \mathrm{~B}$ - nota-se parede dentinária coberta pelo cimento resinoso autoadesivo $\mathrm{U}-200$.
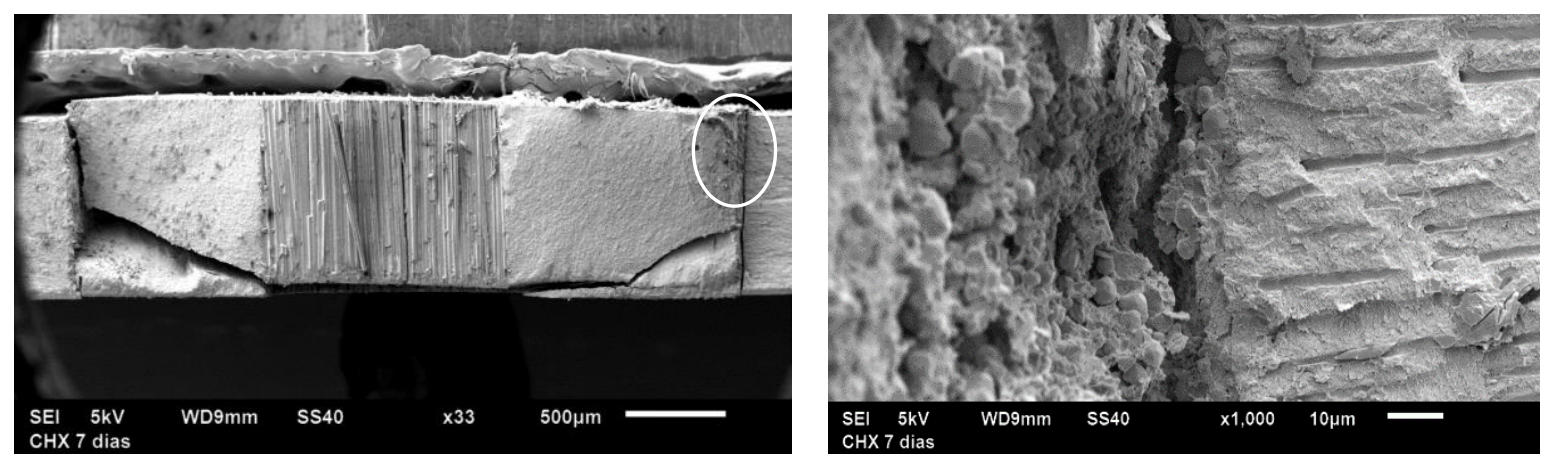

Figuras 10A, 10B - Grupo 4 (CHX 2\% 7 dias). Figura 10A - vista superior da fratura, assinalado, região em que foi realizado o aumento $\times 1000$. Figura $10 \mathrm{~B}$ - nota-se parede dentinária coberta pelo cimento resinoso autoadesivo U-200. 

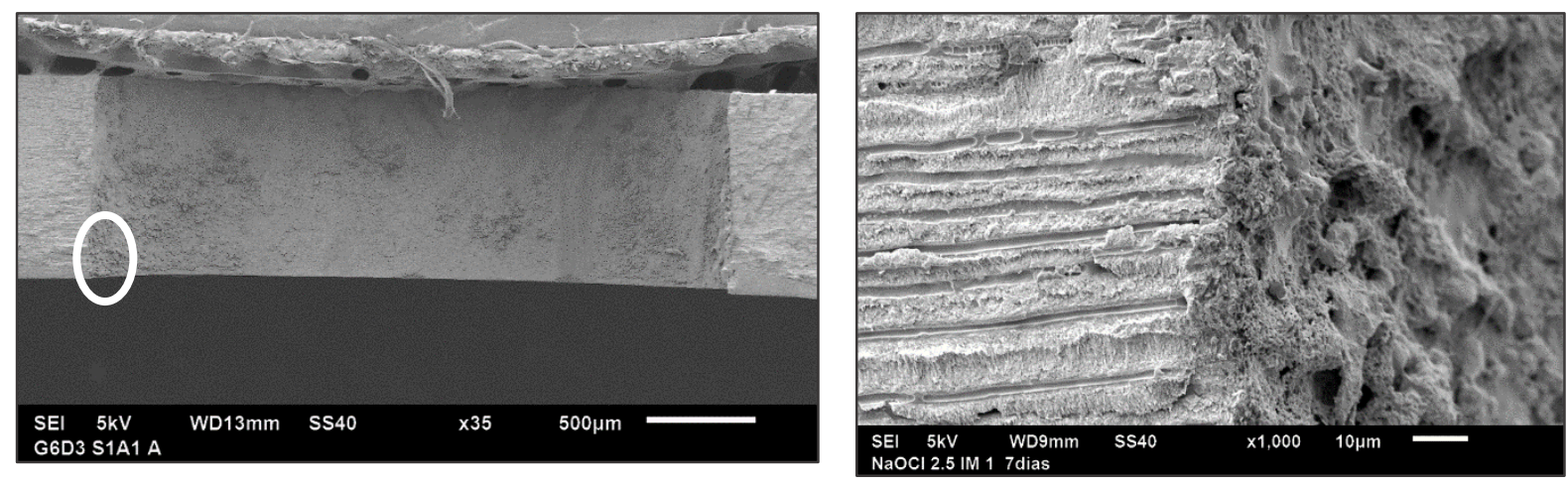

Figuras 11A, 11B - Grupo 5 (NaOCL 2,5\% imediato). Figura 11A - vista superior da fratura, assinalado, região em que foi realizado o aumento x 1000. Figura 11B - nota-se parede dentinária coberta pelo cimento resinoso autoadesivo U-200
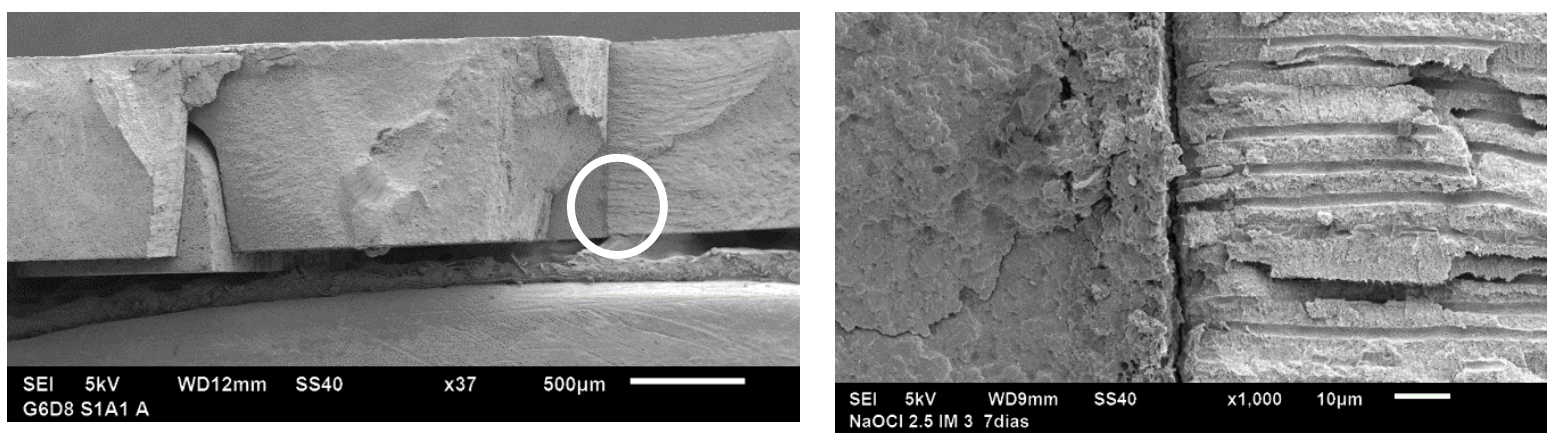

Figuras 12A, 12B - Grupo 6 ( $\mathrm{NaOCL}$ 2,5\% 7 dias). Figura 12A - vista superior da fratura, assinalado, região em que foi realizado o aumento x 1000. Figura 12B - nota-se interfaces da parede dentinária, resina composta e adesivo.
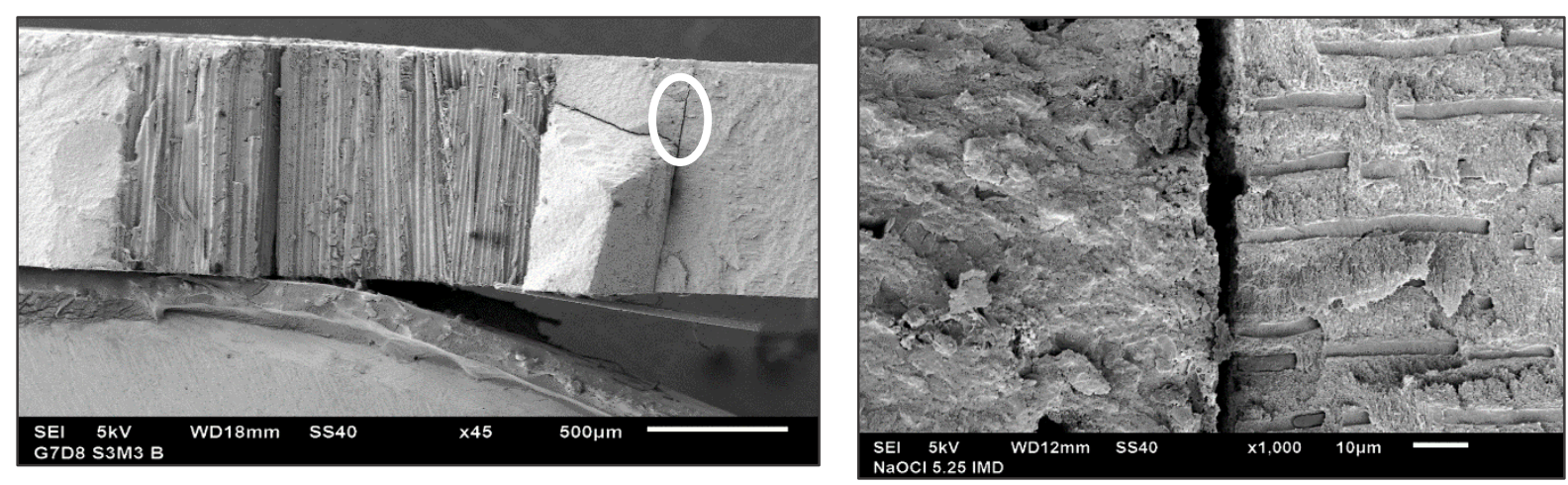

Figuras 13A, 13B - Grupo 7 (NaOCL 5,25\% imediato). Figura 13A - vista superior da fratura, assinalado, região em que foi realizado o aumento x 1000. Figura 13B - nota-se GAP na interface parede dentinária e U-200.
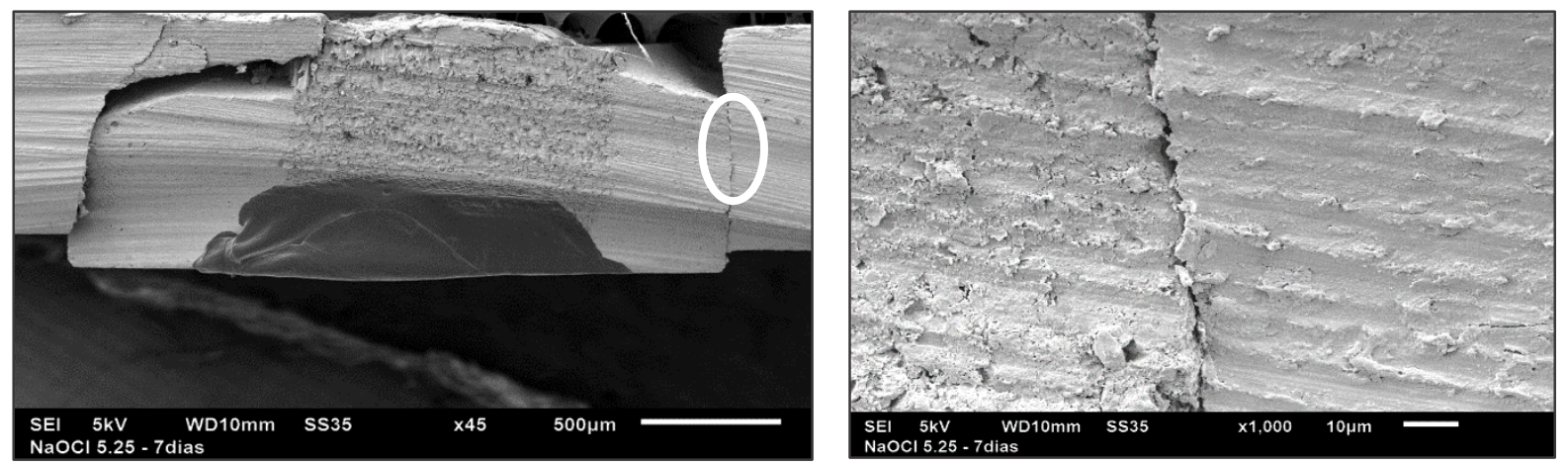

Figuras 14A, 14B - Grupo 8 (NaOCL 5,25\% 7 dias). Figura 14A - vista superior da fratura, assinalado, região em que foi realizado o aumento x 1000. Figura 14B - nota-se interface parede dentinária, e U200 mais justa que no grupo imediato. 
A fim de verificar se o método de limpeza da dentina após a desobturação endodôntica influenciaria nos valores de $\mathrm{RU}$, o conjunto de dados de resistência de união $(\mathrm{MPa})$ à dentina dos pinos anatomizados dos grupos $\mathrm{G} 1 \mathrm{~A}, \mathrm{G} 1 \mathrm{~B}, \mathrm{G} 2 \mathrm{~A}$ e G2B foi submetido a análise de variância a dois critérios fixos ("limpeza" e "tempo"). Foram observadas diferenças significativas em relação ao fator limpeza, tempo e interação entre eles (Tabela 6). A fim de identificar os grupos que diferiram entre si, realizou-se análise de variância a um critério, apresentada na Tabela 7.

Tabela 6 - Resultado da ANOVA a dois fatores (protocolo de limpeza e tempo) para resistência de união à dentina de pinos anatomizados.

\begin{tabular}{l|c|c|c|c}
\hline \multicolumn{1}{c|}{ Fatores } & Grau de liberdade & MS & $\mathbf{F}$ & $\mathbf{P}$ \\
\hline Limpeza & 1 & 560.6 & 38.46 & $0.0000^{*}$ \\
Tempo & 1 & 539.8 & 37.03 & $0.0000^{\star}$ \\
Limpeza \# Tempo & 1 & 103.4 & 7.09 & $0.0086^{\star}$ \\
\hline
\end{tabular}

Tabela 7 - Resultado da ANOVA a dois fatores (protocolo de limpeza e tempo) para resistência de união à dentina de pinos anatomizados.

\begin{tabular}{c|c|c}
\hline $\begin{array}{c}\text { Agente de limpeza da } \\
\text { dentina }\end{array}$ & Período de 0-4 horas & Período de 7 dias \\
\hline $\begin{array}{c}\text { Agua destilada } \\
\text { Álcool absoluto }\end{array}$ & $8.36(1.96) \mathrm{Aa}$ & $10.47(3.03) \mathrm{Aa}$ \\
\hline
\end{tabular}

Letras maiúsculas diferentes indicam diferença significativa entre linhas, e letras minúsculas indicam diferenças significativas entre linhas (Tukey, $p<0.05$ ).

Dessa forma, os grupos submetidos a limpeza com àlcool absoluto apresentaram valores superiores àqueles em que a limpeza foi feita com água destilada apenas para o período de 7 dias. As imagens das figuras 17A,17B,17C/ 18A, 18B,18C/, 19A,19B,19C/, 20A, 20B, 20C/, 21A, 21B, 21C/, 22 A, 22B, 22C/ 23A, 23B,23C/ e 24A, 24B,24C ratificam esses resultados.

As fraturas dos espécimes foram classificadas em (1) A: adesiva - entre o cimento U200 e a dentina, (2) M1: mista - quando o cimento U200 ficou aderido a dentina e quando somado a isso, houve ruptura na interface pino de fibra/ resina composta (figuras 15A, 15B); (3) C: coesiva - quando houve rachaduras nas interfaces além da ruptura adesiva (16C, 16D), conforme apresentado na tabela 8. 
Tabela 8 - Classificação e distribuição das fraturas.

\begin{tabular}{c|c|c|c}
\hline Grupos & Adesiva & Mista & Coesiva \\
\hline 1 A & 0 & 45 & 3 \\
$2 \mathrm{~A}$ & 0 & 45 & 3 \\
3 & 0 & 43 & 5 \\
4 & 0 & 45 & 3 \\
5 & 0 & 47 & 1 \\
6 & 0 & 42 & 6 \\
7 & 0 & 41 & 7 \\
8 & 0 & 42 & 6 \\
\hline
\end{tabular}
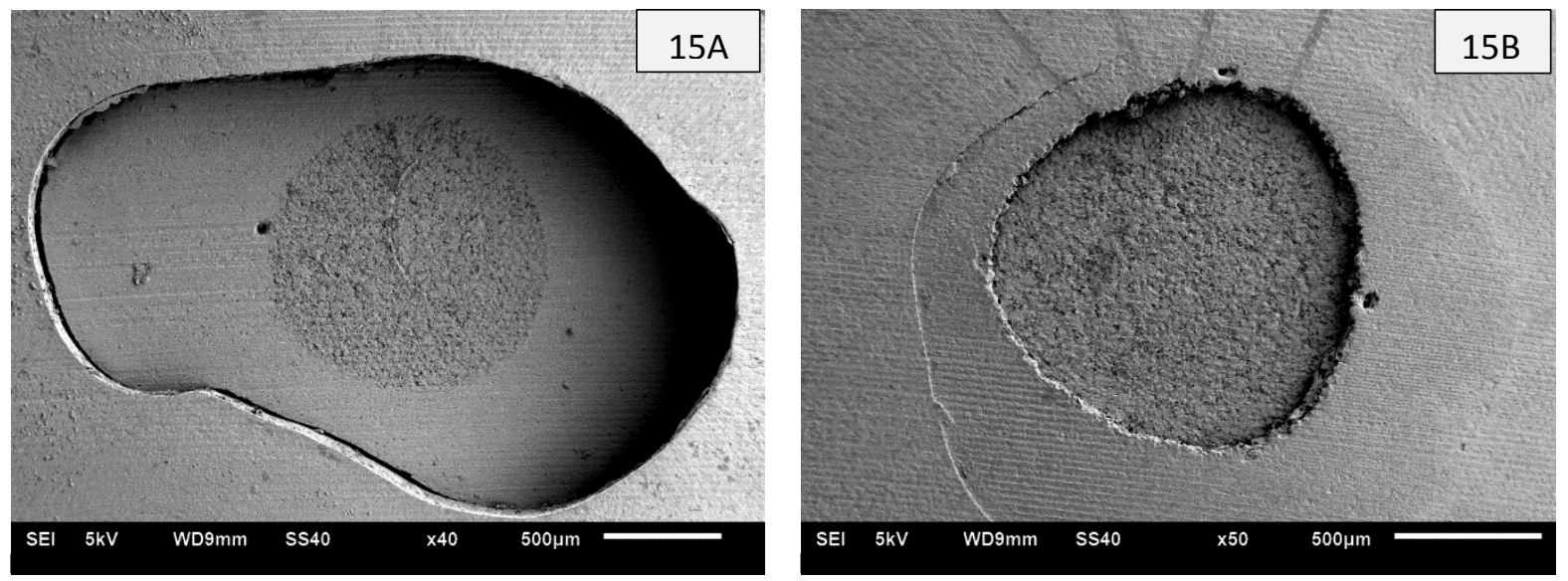

Figuras 15A, 15B - Vista superior dos slices após submetidos ao teste push-out. Exemplos de fraturas mistas. Nota-se em todas as imagens as interfaces pino de fibra/ resina composta, resina composta/ dentina radicular na figura $15 \mathrm{~A}$ houve deslocamento uniforme do conjunto pino de fibra/resina, na figura $15 \mathrm{~B}$ pino de fibra e resina deslocaram em momentos distintos.
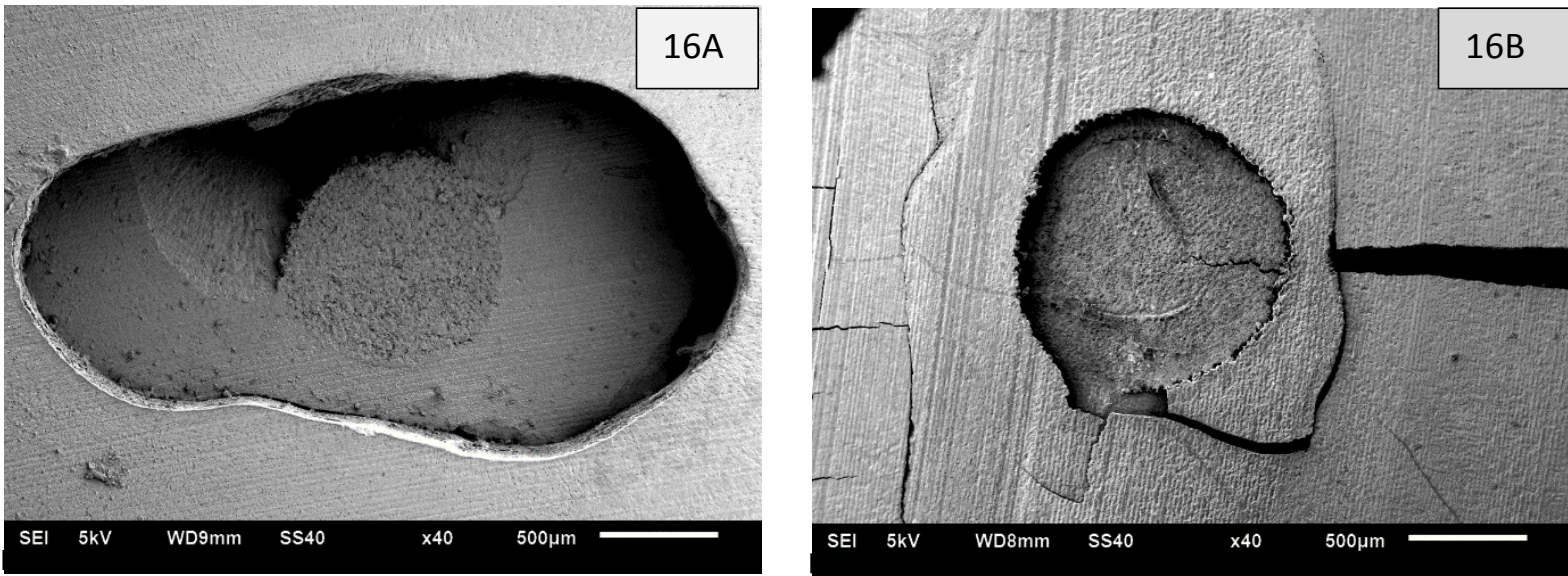

Figuras 16A, 16B - Vista superior dos slices após submetidos ao teste push-out. Exemplos de fraturas coesivas. Figura $16 \mathrm{~A}$ houve deslocamento uniforme do conjunto pino de fibra/resina com fratura de parte da resina composta, na figura $16 \mathrm{~B}$ pino de fibra e resina deslocaram em momentos distintos e houve rachaduras na dentina 

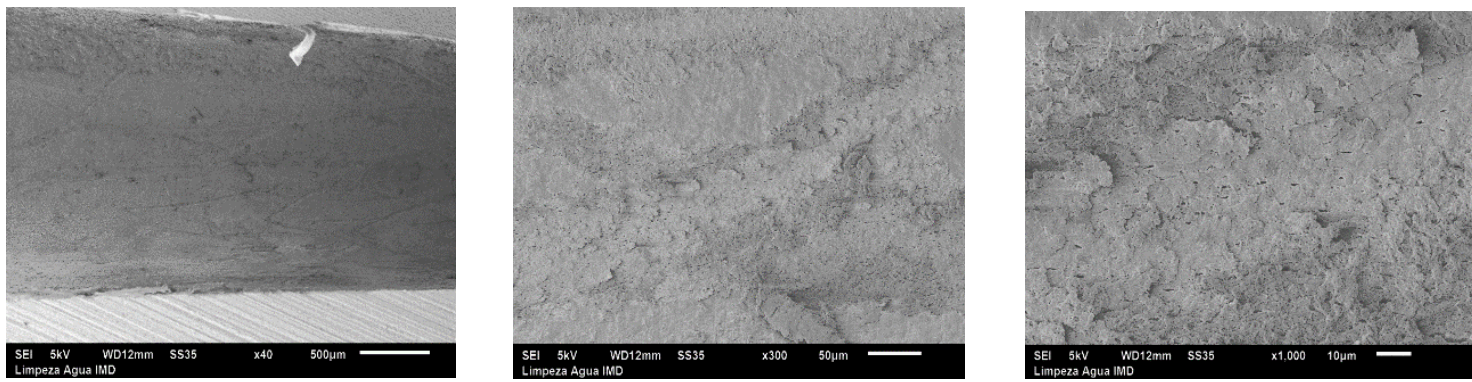

Figuras $17 \mathrm{~A}, 17 \mathrm{~B}, 17 \mathrm{C}$ - Imagens obtidas por MEV do terço médio das raízes que tiveram desobturação imediata (0-4h) e limpeza com água, em três magnificações diferentes. Nota-se presença de camada espessa de esfregaço, provavelmente resíduos orgânicos e inorgânicos produzidos pela ação da broca durante a desobturação do endodonto, obliterando os canalículos dentinários.
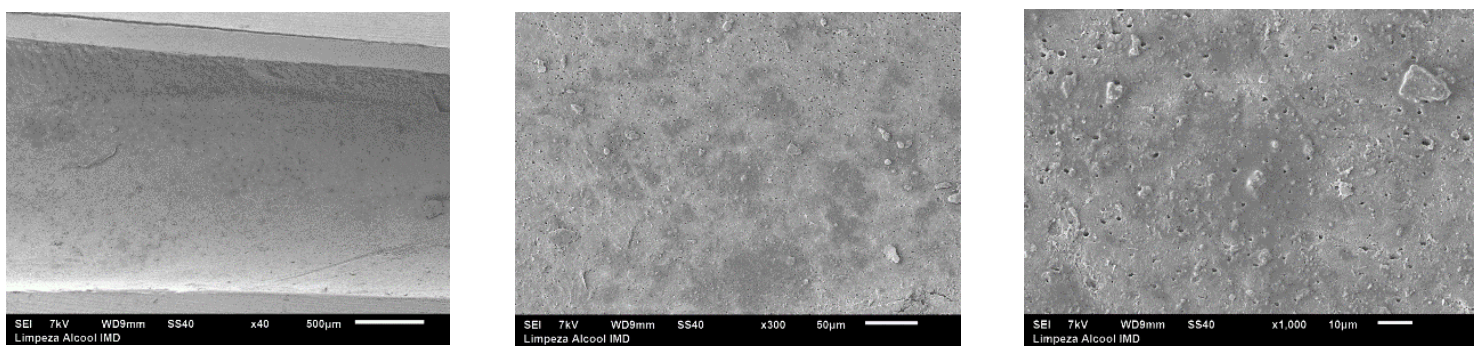

Figuras $18 \mathrm{~A}, 18 \mathrm{~B}, 18 \mathrm{C}$ - Imagens obtidas por MEV do terço médio das raízes que tiveram desobturação imediata (0-4h) e limpeza com álcool absoluto, em três magnificações diferentes. Comparando esse grupo com o anterior, a limpeza com álcool absoluto melhora a condição das paredes dentinárias.
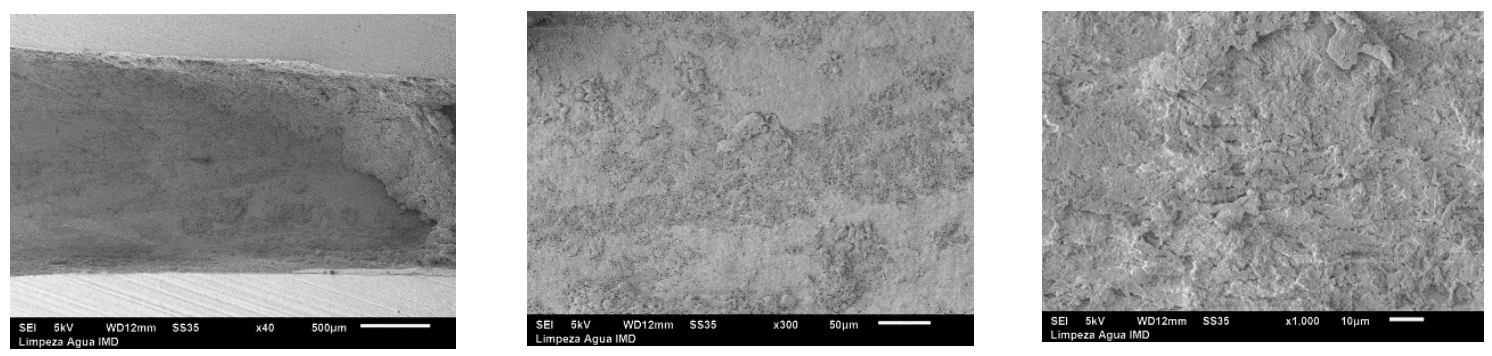

Figuras $19 \mathrm{~A}, 19 \mathrm{~B}, 19 \mathrm{C}$ - Imagens obtidas por MEV do terço apical das raízes que tiveram desobturação imediata (0-4h) e limpeza com água, em três magnificações diferente. Nesse conjunto de imagens da região apical além da camada de esfregaço, resíduos visíveis de material plástico, provavelmente guta-percha plastificada pelo aquecimento da broca.
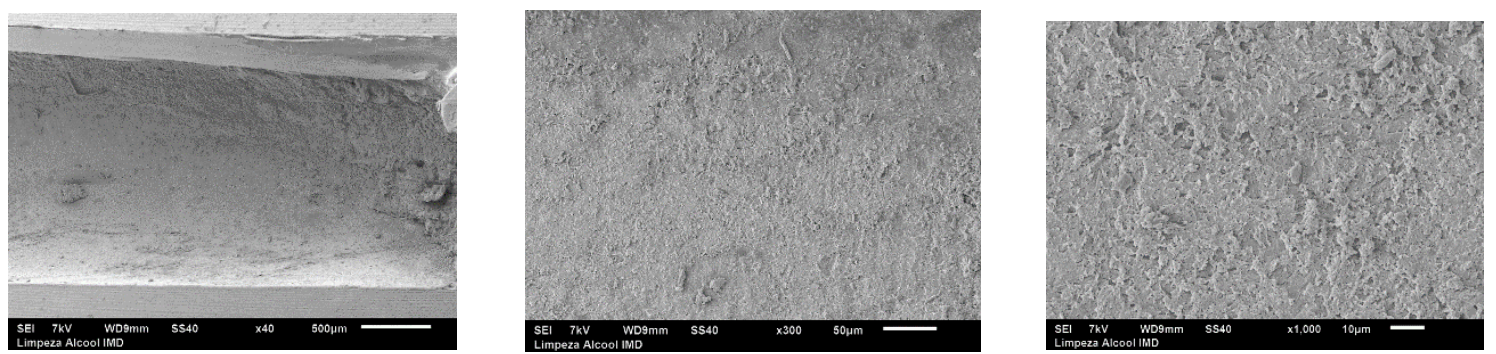

Figuras $20 \mathrm{~A}, 20 \mathrm{~B}, 20 \mathrm{C}$ - Imagens obtidas por MEV do terço apical das raízes que tiveram desobturação imediata (0-4h) e limpeza com álcool absoluto, em três magnificações diferentes. Comparando esse grupo com o anterior, a limpeza com álcool absoluto melhorou a condição das paredes dentinárias. 

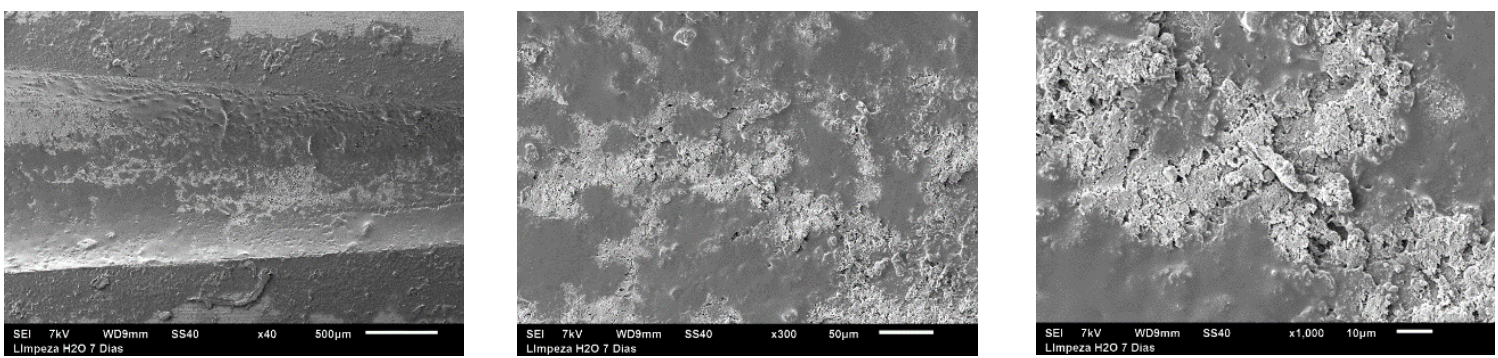

Figuras $21 \mathrm{~A}, 21 \mathrm{~B}, 21 \mathrm{C}$ - Imagens obtidas por MEV do terço médio das raízes que tiveram desobturação após 7 dias e limpeza com água, em três magnificações diferentes. Nota-se presença de artefato, entretanto na magnificação x 1000 camada espessa resíduos orgânicos e inorgânicos são notados,
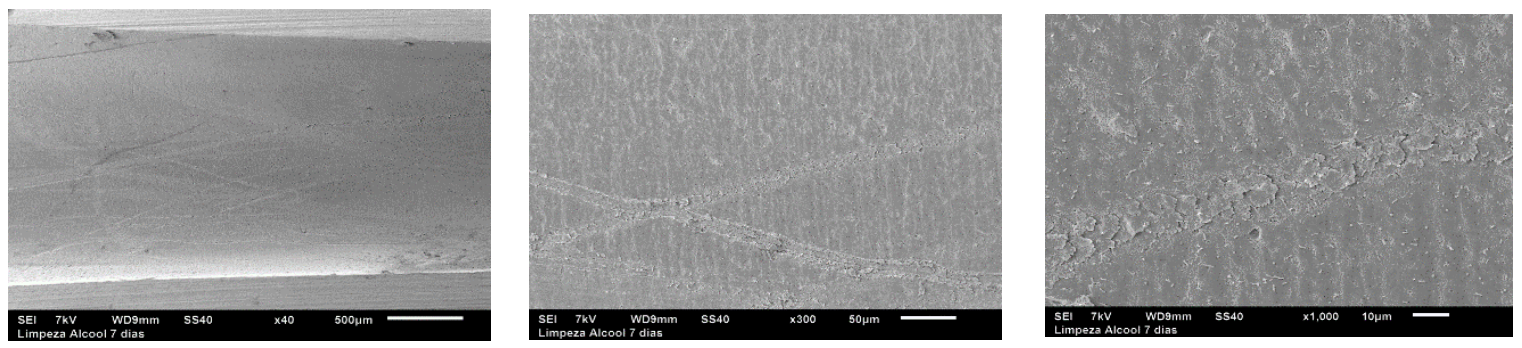

Figuras $22 \mathrm{~A}, 22 \mathrm{~B}, 22 \mathrm{C}$ - Imagens obtidas por MEV do terço médio das raízes que tiveram desobturação após 7 dias e limpeza com álcool absoluto, em três magnificações diferentes. Comparando esse grupo com o anterior a melhora da limpeza com álcool absoluto é notável.
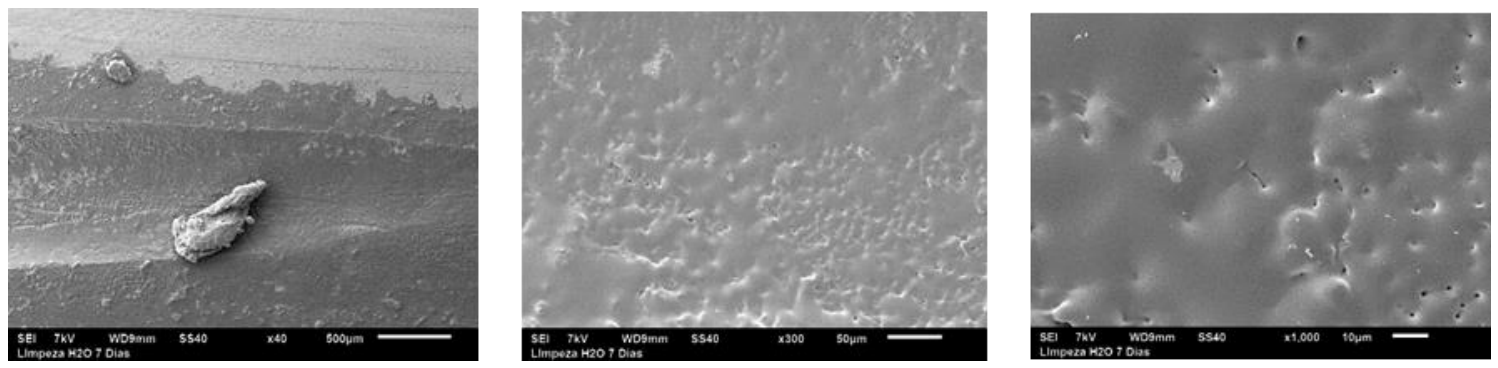

Figuras $23 \mathrm{~A}, 23 \mathrm{~B}, 23 \mathrm{C}$ - Imagens obtidas por MEV do terço apical das raízes que tiveram desobturação após 7 dias e limpeza com água, em três magnificações diferentes. Em comparação com o grupo imediato podemos constatar redução de debris orgânicos e inorgânicos e provavelmente resíduos visíveis de material plástico, provavelmente guta-percha plastificada pelo aquecimento da broca.
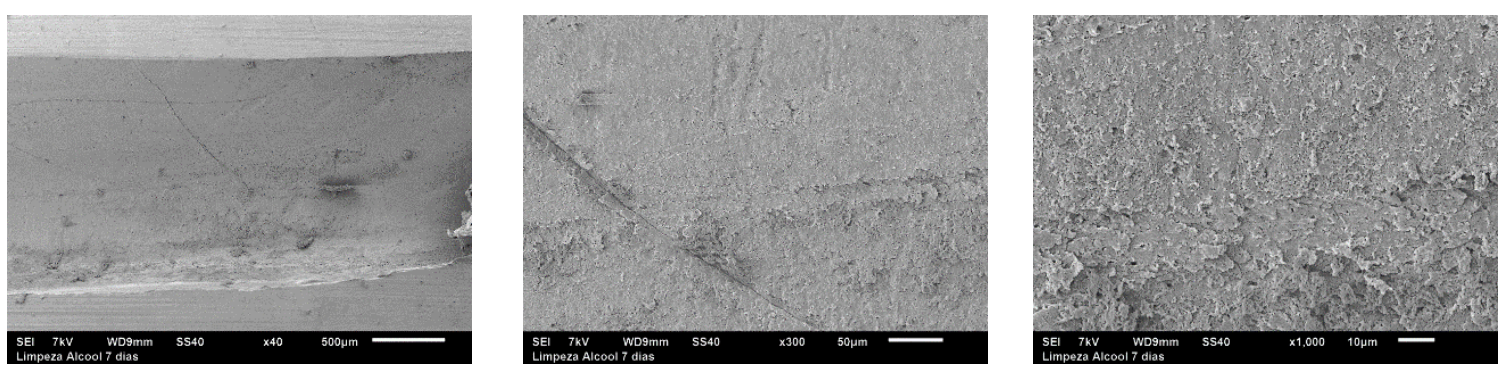

Figuras 24 A, 24 B, 24 C - MEV `S do terço apical das raízes que tiveram desobturação após 7 dias e limpeza com álcool absoluto, em três magnificações diferentes. Em comparação com o grupo imediato podemos constatar redução de debris orgânicos e inorgânicos. 


\section{DISCUSSÃO}

Estudos com pinos anatomizados cimentados com cimento autoadesivo em que se variou as soluções irrigadoras, o tempo de espera para desobturação do canal e o método de limpeza desse conduto são limitados na literatura. Dessa forma, o presente estudo avaliou a influência dos agentes irrigantes, do tempo pós-tratamento endodôntico e método de limpeza na resistência de união de pinos anatômicos à dentina utilizando cimentação autoadesiva por meio de teste micro push-out (12). Os resultados obtidos suportam a rejeição das segunda e terceira hipóteses nulas, em que o tempo de espera para desobturação endodôntica/cimentação do pino anatomizado assim como o método de limpeza influencia os valores de resistência de união à dentina. Já a primeira hipótese nula não foi rejeitada sugerindo que as diferentes soluções endodônticas utilizadas durante a instrumentação não influenciaram os valores de resistência de união à dentina obtidos.

Sabe-se que o uso de soluções químicas irrigantes representa um complemento essencial durante a preparação biomecânica de canais radiculares (6). Contudo ainda não há um consenso na literatura a respeito dos efeitos desses agentes irrigantes sobre a adesão apesar de suas composições químicas alterarem distintamente a superfície dentinária $(6,8,23)$. O hipoclorito de sódio como irrigante endodôntico utilizado em diferentes concentrações (23) apresenta uma ação de amplo espectro antimicrobiano e atua como solvente de tecidos orgânicos e necróticos (21), embora seja altamente irritante aos tecidos periapicais $(6,8)$. Além disso, tem o potencial de atuar nos componentes orgânicos da dentina, em especial nas fibrilas colágenas, podendo influenciar a resistência de união à dentina $(21,23)$.

Em contrapartida, o digluconato de clorexidina ( $\mathrm{CHX}$ ), não interfere nas fibrilas colágenas presentes na matriz orgânica, mantendo a qualidade do substrato dentinário que posteriormente irá interagir com materiais adesivos (1). Esse agente apresenta também ampla atividade antimicrobiana $(1,2,19,20,21$,$) com baixa toxidade$ $(6,23)$ e sua substantividade $(1,2,19,20,21)$ mantém restrita a ação e penetração bacteriana dentro dos túbulos dentinário $(6,19,23)$, sendo inábil na dissolução dos tecidos pulpares $(21,23)$. 
Apesar das diferenças entre esses dois agentes quanto sua ação na dentina, não foram observadas diferenças entre eles quanto a resistência de união à dentina no presente estudo. A opção por utilizar uma solução neutra (água destilada) durante o preparo do conduto radicular para cimentação do pino foi empregada em virtude do tipo de cimento utilizado e uma forma de simular essa cimentação clinicamente, uma vez que o fabricante do cimento resinoso autoadesivo U-200 recomenda a irrigação do canal radicular com $\mathrm{NaOCl}$ seguido por água (11). Observou-se que mesmo após a irrigação com diferentes agentes endodônticos durante o tratamento endodôntico, a desobturação do conduto radicular com brocas e irrigação com água destilada anulou qualquer possível efeito residual dessas soluções sobre a camada híbrida por um período de 7 dias.

Efeito residual de espécies reativas de oxigênio estão comumente associadas a falhas na adesão, como observado em restaurações realizadas imediatamente (19) ou curto período após o clareamento dentário $(19,26)$. Assim, esperava-se que raízes tratadas com hipoclorito de sódio pudessem apresentar algum efeito residual dessas espécies reativas de oxigênio, o que não foi confirmado no presente estudo. A cimentação autoadesiva (5), por não requerer tratamento prévio da dentina com ácido fosfórico, apresenta uma camada híbrida pouco espessa e limitada a superfície dentinária (17). Os cimentos resinosos autoadesivos são formulados com monômeros ácidos funcionais $(5,10,17,27)$ tais como o éster fosfórico metacrilato, que servem como uma matriz de resina, bem como solução condicionadora (10) capazes de desmineralizar e infiltrar os tecidos dentais $(5,10,17)$. Além de bloqueio mecânico, o mecanismo de união principal é atribuído a uma reação química entre os ácidos metacrilatos de fosfato e íons de cálcio da hidroxiapatita $(5,10,17,19)$, bem como a presença de íons alcalinos lixiviados a partir de partículas de vidro ácidos solúveis no cimento resinoso autoadesivos, fazem com que estes materiais tendem a ficar mais hidrofóbico com o tempo. São hidrofílicos e têm um carácter ácido, especialmente nos momentos iniciais após a mistura dos componentes, características importantes para a humidificação adequada da dentina radicular e condicionamento de superfície, resultando num aumento da resistência de união $(10,17)$. Sendo assim, a partir dos resultados obtidos no presente estudo, independente da solução irrigadora utilizada durante a instrumentação do conduto radicular, se a desobturação for realizada com brocas e irrigação com água, uma nova smear layer é criada uniformizando a dentina 
com a qual o cimento autoadesivo terá contato, anulando qualquer efeito residual das soluções irrigadoras prévias.

Em relação a segunda hipótese nula, o fator tempo de espera para desobturação do conduto radicular e cimentação do pino anatomizado interferiu significativamente nos valores de resistência da união à dentina. Para todos os grupos experimentais e controle, os valores de resistência de união obtidos na desobturação endodôntica/ cimentação autoadesiva de pino anatômico imediata foram menores aos que tiveram intervalo de 7 dias. Apesar de não haver consenso quanto ao intervalo de tempo adequado entre estas etapas, nossos resultados corroboram com os resultados encontrados por Rosa et al e Vano et al $(9,28)$ no qual também foi avaliado diferentes intervalos entre final do tratamento endodôntico e cimentação de pino de fibra e utilizado cimento AH PLUS e guta-percha. Para ambos estudos, os maiores valores de resistência de união à dentina foram obtidos quando o intervalo desobturação endodôntica/ cimentação autoadesiva de pino anatômico foi de 7 dias. Considerando não ter havido modificação na smear layer para todos os grupos experimentais, tal fato pode ser justificado pelo maior tempo de presa que o AH PLUS obteve num intervalo de tempo maior (9). O cimento encontrava-se mais cristalizado (11) e por isso foi removido em maior quantidade no procedimento de desobturação/ preparação do espaço para o pino de fibra anatômico, deixando uma superfície mais limpa e beneficiando a adesão do cimento resinoso autoadesivo à dentina. Nas micrografias do grupo em que a desobturação foi realizada nas primeiras 24 horas observa-se presença de cimento endodôntico assim como guta-percha, deixando uma smear layer mais suja, a qual influenciou negativamente os valores de resistência de união. Dessa forma, a presa completa do cimento ou mesmo a obturação somente do terço apical são estratégias indicadas para que os pinos de fibra anatomizados apresentem a melhor performance clínica.

O presente estudo utilizou pinos anatomizados $(1,2,4,20)$ em que o pino de fibra é reajustado dentro do canal radicular substituindo, em parte, o cimento resinoso pela resina composta, que tem melhores propriedades mecânicas e físicas (4). Nesta técnica a espessura do cimento resinoso é reduzida $(1,4)$ devido à pressão hidráulica alta que exercem sobre o cimento contra as paredes de dentina, resultando em melhor contato entre o cimento/ pino e dentina. Esta pressão reduz a formação de bolhas no cimento, eliminando assim as tensões em locais de iniciação de falha, aumentando o número de túbulos preenchidos com cimento de resina devido a uma melhor 
penetração do cimento resinoso na dentina desmineralizada, resultando em uma camada híbrida mais uniforme e com o tags mais longos, além de ramificações adesivas laterais $(4,23)$. Propriedades que talvez justifiquem não ter havido diferença entre os terços cervical, médio e apical nos resultados de resistência de união. As imagens obtidas por MEV da dentina bovina apenas instrumentada também evidenciou uma quantidade menor de smear layer formada no terço apical, achado este que também pode relacionado aos resultados equivalentes desta porção em relação as outras, uma vez que os monômeros acídicos do cimento resinoso podem ter atuado de maneira expressiva nessa camada de esfregaço mais delgada.

A terceira hipótese nula acerca da limpeza do conduto radicular após desobturação endodôntica com água ou álcool também foi rejeitada, uma vez que o grupo em que a limpeza foi realizada com álcool após 7 dias da obturação do contudo apresentou valores superiores aos demais (G2B). O uso do álcool ou mesmo acetona é recomendada pelo fabricante do cimento endodôntico para limpeza dos instrumentais que entram em contato com esse cimento durante o procedimento clínico. Considerando que a presa final desse cimento ocorre após 24 horas, especulou-se que quando desobturado antes desse período, o conduto radicular permaneceria mais sujo com resíduos de cimento e guta-percha, o que pode ser visualizado nas imagens obtidas na MEV. Ainda, foi sugerido que a limpeza com um solvente orgânico, tal como álcool, removeria melhor esses resíduos aumentando os valores de RU dos pinos anatomizados cimentados com cimento autoadesivo. Sabese que esse cimento, devido às suas características químicas, é incapaz de estabelecer com a dentina uma camada híbrida com tags longos, sendo o contato com uma dentina limpa um requisito essencial para adesão. Dessa forma, o protocolo de limpeza com álcool absoluto após a desobturação endodôntica promoveria uma dentina mais limpa para que se estabelecesse uma adesão adequada.

Parte dos nossos resultados reforçaram essa ideia, uma vez que para o grupo de 7 dias, foi observada valores superiores aos demais grupos quando se realizou a limpeza com álcool. Para o grupo imediato, observa-se um aumento dos valores de RU para o grupo limpo com álcool (G1B), ainda que não tenha sido observada uma significância estatística. Acredita-se que essa significância não foi observada devido aos maiores valores de desvio-padrão para os grupos do álcool.

$\mathrm{Na}$ literatura o pesquisada nenhum trabalho que replicasse essa limpeza com álcool absoluto por meio da fricção nas paredes radiculares de lima endodôntica 
envolta com algodão estéril, seguido de irrigação com água destilada com finalidade de reidratar a dentina, foi encontrado. Cecchin et al (20) em 2011 usou o álcool sozinho ou associados à clorexidina $2 \%$ como alternativa de pré-tratamentos da dentina radicular bovina apenas instrumentada com solução salina $(\mathrm{NaCl})$, após condicionamento com ácido fosfórico, ou seja, o endodonto não foi obturado com cimento endodôntico. Dessa forma, mais estudos com objetivo de estabelecer protocolos que permitam a desobturação imediata e consequente cimentação do pino anatomizado em uma mesma sessão clínica são necessários. 


\section{CONCLUSÃO}

Diante das limitações do presente estudo, foi possível concluir que:

a) Em relação às soluções irrigadoras, não houve diferença entre clorexidina, hipoclorito e soro fisiológico, de forma que quando se utiliza um protocolo único de desobturação (água destilada), o possível efeito residual das soluções irrigantes é anulado.

b) O tempo de espera para desobturação do conduto radicular e cimentação do pino influenciou diretamente os valores de resistência de união de pinos anatomizados cimentados com cimento autoadesivo à dentina. $O$ tempo de espera mais longo (7 dias) para desobturação do conduto radicular e cimentação do pino anatomizado resultados em maiores valores de RU.

c) O método de limpeza do conduto radicular após a desobturação endodôntica influenciou os valores de RU apenas para o período de 7 dias. 


\section{REFERÊNCIAS BIBLIOGRÁFICAS}

1. Cecchin D, Almeida JF, Gomes BP, Zaia AA, Ferraz CC. Influence of chlorhexidine and ethanol on the bond strength and durability of the adhesion of the fiber posts to root dentin using a total etching adhesive system. J Endod 2011; 37:1310-15.

2. Cecchin D, Giacomin M, Farina AP, Bhering CLB, Mesquita MF, Ferraz CCR. Effect of Chlorhexidine and Ethanol on Push-out Bond Strength of Fiber Posts under Cyclic Loading. J Adhes Dent 2014; 16:87-92.

3. Clavijo VGR, Bandeca MC, Clavijo MB, Clavijo EMA, Itikawa GN, Andrade MF. Personalização do Pino de Fibra de Vidro com Resina Composta - Pino Anatômico. International Journal of Brazilian Dentistry 2009; 5(4): 384-96.

4. Gomes GM, Gomes OMM, Gomes JC, Loguercio AD, Calixto AL, Reis A. Evaluation of Different Restorative Techniques for Filling Flared Root Canals: Fracture Resistance and Bond Strength After Mechanical Fatigue. J Adhes Dent 2014; 16: 267-76.

5. Dimitrouli M, Günay H, Geurtsen W, Lührs AK. Push-out strength of fiber posts depending on the type of root canal filling and resin cement. Clin Oral Invest $2011 ; 15: 273-81$.

6. Pelegrine RA, De Martin AS, Cunha RS, Pelegrine AA, Bueno CES. Influence of chemical irrigants on the tensile bond strength of an adhesive system used to cement glass fiber posts to root dentin. Oral Surg Oral Med Oral Pathol Oral Radiol Endod 2010; 110:73-6.

7. Santana FR, Soares CJ, Silva JA, Alencar AHG, Renovato SR, Lopes LG, Estrela C. Artifcial accelerated Aging on Fiberglass Post Bond Strength to Intraradicular Dentin. J Contemp Dent Pract. 2015; 16(7):523-30. 
8. Farina AP, Cecchin D, Barbizam JVB, Júnior BC. Influence of endodontic irrigants on bond strength of a self-etching adhesive. Aust Endod J 2011; 37: 26-30.

9. Rosa RA, Barreto MS, Moraes RA, Broch J, Bier CAS, Só MVR, et al. Influence of Endodontic Sealer Composition and Time of Fiber Post Cementation on Sealer Adhesiveness to Bovine Root Dentin. Braz Dent J. 2013; 24(3): 241-46.

10. Faria-e-Silva AL, Menezes MS, Silva FP, Reis GR, Moraes RR. Intra-radicular dentin treatments and retention of fiber posts with selfadhesive resin cements. Braz Oral Res 2013 Jan-Feb; 27(1):14-9.

11.K AIEisa, ZN Al-Dwairi, E Lynch, CD Lynch. In Vitro Evaluation of the Effect of Different Endodontic Sealers on Retentive Strength of Fiber Posts. Oper Dent. 2013; 38 (5):539-44.

12. Soares CJ, Santana FR, Castro CG, Santos-Filho PCF, Soares PV, Qian F et al. Finite element analysis and bond strength of a glass post to intraradicular dentin: Comparison between microtensile and push-out tests. Dent Mater 24 (2008) 1405-11.

13. Leitune VCB, Collares FM, Samuel SMW. Influence of chlorhexidine application at longitudinal push-out bond strength of fiber posts. Oral Surg Oral Med Oral Pathol Oral Radiol Endod 2010; 110:77- 81.

14. Kremeiera K., Fasen L., Klaiber B., Hofmann N. Influence of endodontic post type (glass fiber, quartz fiber or gold) and luting material on push-out bond strength to dentin in vitro. Dent Mater 2008; 24: 660-66.

15. Arslan H, YIImaz CB, Karatas E, Barutcigil C, Topcuoglu HS, Yeter KY. Efficacy of different treatments of root canal walls on the pull-out bond strength of the fiber posts. J Lasers Med Sci 2015; 30:863-8. 
16. Zhou J, Yang X, Chen L, Liu X, Ma L, Tan J. Pre-treatment of radicular dentin by self-etch primer containing chlorhexidine can improve fiber post bond durability. Dent Mater 2013; 32(2): 248-55.

17. Faria-e-Silva AL, Peixoto AC, Borges MG, Menezes MS, Moraes RR. Immediate and delayed photoactivation of self-adhesive resin cements and retention of glass-fiber posts. Braz Oral Res 2014; 28(1):1-6.

18. Menezes MS, Queiroz EC, Soares PV, Faria-e-Silva AL, Soares CJ, Martins LRM. Fiber Post Etching with Hydrogen Peroxide: Effect of Concentration and Application Time. J Endod. 2011; 37(3): 398-402.

19. Lindblad RM, Lassila LV, Salo V, Vallittu PK, Tja"derhane L. Effect of chlorhexidine on initial adhesion of fiber-reinforced post to root canal. J Dent. 2010; 38:796-801.

20. Cecchin D, Almeida JF, Gomes BP, Zaia AA, Ferraz CC. Effect of chlorhexidine and ethanol on the durability of the adhesion of the fiber post relined with resin. J Endod 2011; 37: 678-83.

21.Bitter K, Hambarayan A, Neumann K, Blunck U, Sterzenbach G. Various irrigation protocols for final rinse to improve bond strengths of fiber posts inside the root canal. Eur J Oral Sci 2013; 121: 349-54.

22. Castellan CS, Cardoso PEC. Comparação dos ensaios de microtração, pushout e pull-out na avaliação da adesão entre pino de fibra e dentina radicular por meio da mensuração da resistência de união. Rev Pós Grad 2011; 18(3):12733.

23. Moreira DM, Almeida JFA, Ferraz CCR, Gomes BPFA, Line SRP, Zaia AA. Structural Analysis of Bovine Root Dentin after Use of Different Endodontics Auxiliary Chemical Substances. J Endod 2009; 35:1023-27. 
24. Jardim PS, Pereira-Cenci T, Badin C F, Ferreira ACA, Jacinto R C. The effect of endodontic chemicals on the retention of fiber posts luted using a selfadhesive cement. Applied Adhesion Science 2014, 2:20.

25. Stevens CD. Immediate Shear Bond Strength of Resin Cements to Sodium Hypochlorite - treated Dentin. J Endod. 2014; 40:1459-62.

26. Marshall GW JR, Yucel N, Balloch M, Kinney JH, Habelitz S, Marshall SJ. Sodium hypoclorite alterations of dentin and dentin collagen. Surf. Sci. 2001; 491:444-55.

27. Hikita K, Van Meerbeek B, De Munck J, Ikeda T, Van Landuyt K, Maida et al. Bonding effectiveness of adhesive luting agents to enamel and dentin. Dent Mater 2007; 23:71-80.

28. Vano M, Cury AH, Goracci C, Chieffi N, Gabriele M, Tay FR, Ferrari M. Retention of fiber posts cemented at different time intervals in canals obturated using an epoxy resin sealer. J Dent. 2008; 36:801-07. 